\title{
EFECTOS DEL CUMPLIMIENTO DE LA CONDENA PRECEDENTE EN EL ACCESO AL RÉGIMEN DE PENAS SUSTITUTIVAS PREVISTAS EN LA LEY 18.216. CONSIDERACIONES SOBRE EL ESTATUTO APLICABLE A LA REITERACIÓN DELICTIVA, AL MARGEN DE LA AGRAVANTE DE REINCIDENCIA*
}

\section{FranCISCO MALDONADO FUENTES**}

RESUMEN: La responsabilidad penal de quien recae o reitera en la comisión de delitos se somete a un régimen de efectos particulares que no se encuentran previstos en las reglas generales. Entre ellos se considera una drástica limitación al régimen de penas sustitutivas previstas en la Ley chilena, restricción que cesa si se constata el transcurso de un determinado tiempo desde la fecha de cumplimiento de la pena impuesta en forma similar a cómo sucede con respeto a algunos de los demás efectos previstos en este estatuto en particular. El artículo busca problematizar acerca de los fundamentos de dicha restricción y de su cese, como también acerca de lo que debe entenderse por cumplimiento de la pena a dichos efectos, asumiendo una interpretación extensiva en base a los motivos que informan la correspondiente decisión legislativa. Para ello, se desarrolla la diferencia existente entre el cumplimiento de la pena impuesta y el cumplimiento de la condena, como también los casos que quedan comprendidos bajo dichos supuestos.

Palabras Clave: Cumplimiento de condena - cumplimiento de pena - responsabilidad penal - reiteración delictiva - Ley 18.216.

El texto forma parte del proyecto Fondecyt $N^{\circ} 1121313$, financiado por Conicyt, referido al tratamiento de la reiteración delictiva en Derecho penal, del cual el autor es investigador responsable. Agradezco la revisión, comentarios y sugerencias recibidas de parte del profesor Dr. Sebastián Salinero E. y del Sr. Gonzalo Bascur R., ayudante de investigación asociado al proyecto.

Fecha de recepción: 24 de septiembre de 2014

Fecha de aceptación: 5 de mayo de 2015.

** Abogado. Doctor en Derecho. Subdirector del Centro de Estudios de Derecho Penal de la Universidad de Talca (CHILE). Profesor e Investigador de la Facultad de Ciencias Jurídicas y Sociales de esa misma casa de estudios. Correo electrónico: frmaldonado@utalca.cl. 


\title{
Effects on The Execution of The Sentence on The Precedent Regarding The ACCess to The Applicable System of Alternative SENTENCES Provided by The LaW 18.216. CONSIDERATIONS ON THE STATUTE APPLICABLE To The Criminal Reiteration Apart From The Aggravating CirCuMSTANCE OF RECIDIVISM
}

\begin{abstract}
The criminal liability of a subject who repeatedly commits a felony or falls back into it is ruled by an special statute of law that provides particular effects over those acts, which are not provided by the general rules of law. Among those effects, there is a drastic limitation to the applicable system of alternative sentences provided in the Chilean law. This restriction cease if a period of time has passed from the date of execution of the sentence imposed. It happens in a similar way to some of the other purposes specified in this particular statute. This article seeks to discuss about the basics of this restriction and its cessation, as well as what should be understood by execution of the sentence for such purposes, assuming a broad interpretation based on motives that inform the legislative decision. To perform this, the situation is reviewed by looking for the existing difference between the execution of the sentence imposed and the execution of the sentence, and together with the cases under such assumptions.
\end{abstract}

KEY WORDS: Execution of the sentence imposed - execution of the sentence - criminal liability - recidivism - Law 18.216.

\section{1) Planteamiento del problema}

La constatación de una recaída en el delito resulta determinante para resolver la procedencia y características de las penas sustitutivas previstas en la ley 18.216 respecto de las condenas privativas o restrictivas de liber$\operatorname{tad}^{1}$. En efecto, dichas penas sustitutivas no resultan aplicables a quienes han sido previamente condenados por la comisión de un crimen o simple delito -entre otras exclusiones-, configurando modalidades de sanción

En este sentido: Garrido Montt, Mario (2007) Derecho Penal: Parte General. Nociones Fundamentales de la Teoría del Delito. Tomo II. 4a Edición. Santiago: Editorial Jurídica de Chile, 858 pp., p. 209. 
que, en principio, se consideran solo para quienes son sindicados en jerga común como "primerizos"2.

Dicha restricción aparece justificada en consideración al fundamento de la imposición sustitutiva de las penas alternativas, en cuanto radicada en la afirmación de un pronóstico de socialidad favorable respecto de quien es condenado por ciertas penas (de mediana o baja entidad) ${ }^{3}$, afirmación que resultaría cuestionada por la constatación de la comisión de delitos en su historial de vida. Tras ello se interpreta la recaida, en cuanto dato fáctico, como un obstáculo a la formulación de dicho pronóstico "favorable", asumiendo que la constatación de una condena previa pone en evidencia que el delito no constituiría un hecho aislado (o "algo ocasional') en el comportamiento de vida del condenado. In extenso, subyace una especie de pronóstico asociado a una probable recaída futura. Bajo estas condiciones se entiende que dicha suposición contribuye a sostener que la ejecución de la condena privativa de libertad que correspondería imponer conforme a las reglas generales resulta innecesaria o, inclusive, contraproducente para la reinserción del condenado, lo que no sucedería respecto a los reiterantes ${ }^{4}$.

Dicho estatuto ha sido sustantivamente modificado en este punto en particular en forma reciente, afectándose también con ello el tratamiento concedido al significado que es posible atribuir a la recaída en el delito. El nuevo texto del inciso final del artículo $1^{\circ}$ de la Ley 18.216, introducido por la Ley 20.603 (publicada en el Diario Oficial el 27 de junio de 2012) dispone concretamente que para su aplicación (de la Ley, en forma íntegra) "no se considerarán las condenas por crimen o simple delito cumplidas, respectivamente, cinco o diez años antes de la comisión del nuevo ilícito", regla general que busca precisamente privar de eficacia al efecto excluyente que producen las condenas penales precedentes, habilitándose con ello el acceso de los reiterantes al régimen de los sustitutivos ${ }^{5}$. Tras ello pareciera

2 La excepción la constituye el régimen previsto para la reclusión parcial (y, en el texto original, para la reclusión nocturna) en cuanto permite la sustitución respecto de quienes hubieren sido condenados por uno o mas delitos, en tanto la condena o condenas impuestas no superen los 2 años de privación o restricción de libertad. Véase el art. 8 letra b) de la Ley 18.216.

3 Sobre ello: Etcheberry Orthusteguy, Alfredo (2004) Derecho Penal: Parte General. Tomo I. 3a Edición. Santiago: Editorial Jurídica de Chile, 269 pp., p. 202. Garrido (2007) 342. Implícito en el nexo establecido entre las ideas expresadas en el texto y la orientación hacia la prevención especial en: Ortiz Quiroga, Luis; Arévalo Cunich Javier (2013) Las consecuencias jurídicas del delito. Santiago: Editorial Jurídica de Chile, 605 pp., p. 157.

4 Sobre ello: Cury Urzúa, Enrique (2005) Derecho Penal. Parte General. 7a Edición. Santiago: Ediciones Universidad Católica de Chile, 812 pp., p. 729; Garrido (2007) 339; Ortiz y Arévalo (2013) 157.

5 Conviene tener presente que el criterio no fe considerado en dichos términos en los orígenes de la iniciativa. Inicialmente fue propuesto respecto de las condenas previas por simple delito y una vez que transcurrieren 10 años desde el cumplimiento. Fue solo en la discusión particular del primer trámite constitucional en la H. Cámara de Diputados que se acordó el 
que el legislador asume que el solo transcurso del tiempo "sin delito" neutraliza el pronóstico negativo de futuro al que hemos aludido precedentemente ${ }^{6}$.

En efecto, se trata de una constatación que relativiza la presunción de una prognosis negativa centrada en la presencia de condenas previas, pues, en cierta forma, se considera que la existencia de una distancia temporal relevante entre el delito que se sanciona en términos actuales y una condena precedente permite rechazar la propia relevancia asignada a la apreciación de una reiteración o recaída 7 . Dicho dato hace equivalente este caso al de quien delinque en forma meramente "ocasional", pasando por ello a configurarse su situación en conformidad con dicha lectura ${ }^{8}$.

El tenor literal de la disposición que nos ocupa ("no se considerarán" dichas condenas) y su propia ubicación sistemática ${ }^{9}$, evidencian claramente que dicho efecto debe ser apreciado y aplicado en forma absoluta. Con ello resulta posible concluir que la presencia de dichos antecedentes

criterio, inicialmente para la remisión condicional de la pena y luego para todos los demás sustitutivos previstos. Véase: Biblioteca del Congreso Nacional. Historia de la Ley $\mathrm{N}^{\circ}$ 20.603. Modifica la ley 18.216, que establece medidas alternativas a las penas privativas o restrictivas de libertad. Disponible en: http://www.leychile.cl/Navegar/scripts/obtienearchi vo?id=recursoslegales/10221.3/37271/1/HL20603.pdf [fecha de visita 22 de septiembre de 2014] pp. 108, 116 y 125.

6 Ortiz y Arévalo (2013) 158, en un sentido similar, destacan que "Con ello se reconoce el que los antecedentes prontuariales - al menos para estos efectos- no son eternos y que si un sujeto, aun habiendo delinquido de manera pretérita mantiene durante un largo periodo un comportamiento socialmente irreprochable, no debe ser estigmatizado ni verse privado de acceder a las penas sustitutivas".

7 Expresamente sostuvieron los promotores de la reforma legal (si bien con un texto aun diverso y más restrictivo respecto de aquel que finalmente fue aprobado) que "si transcurre un tiempo mayor entre la condena antigua y el nuevo delito, no debería considerarse como reincidente", Biblioteca del Congreso Nacional, 71.

8 Deseable hubiera sido el que se hubiere reconocido el mismo efecto en otro tipo de presupuestos en que resulta factible sostener una conclusión similar. Así por ejemplo, respecto de quien presenta una condena previa fundada en un delito imprudente (a menos que se trate de una nueva infracción de la misma clase); respecto de los casos en que concurre en el historial un atentado patrimonial y su incidencia en la imposición de una condena fundada en uno de carácter personal (lesiones, homicidio, etc.). Sobre ello, con un criterio equivalente al primer caso mencionado y con apoyo jurisprudencial Ortiz y Arévalo (2013) 158.

9 A este respecto hay que tener en cuenta que la limitación y su respectiva excepción se establece en forma particular respecto de cada una de las penas sustitutivas. Así, respecto de la remisión condicional de la pena, en el art. $4^{\circ}$ letra b); respecto de la libertad vigilada, en el numeral $1^{\circ}$ del inciso segundo del art. 15; respecto de la libertad vigilada intensiva, en el inciso final del art. 15 bis.; y respecto del régimen de pena mixta, conforme dispone el art. 33 letra b) (que se remite al inciso final de dicha disposición la que, a su vez, se remite al inciso segundo del art. 15 bis. que contiene la regla). Aplica también, de forma relativa, a la reclusión parcial conforme dispone el art. $8^{\circ}$ letra b), teniendo en cuenta que, según ya apuntamos, se trata de un sustitutivo que procede igualmente respecto de quienes tuvieren una o más condenas precedentes cuya duración no supere los dos ańos de privación o restricción de libertad. Con ello, no parece que la previsión inicial (en el artículo $1^{\circ}$ ) y general de dicho contenido tenga un sentido diverso al de consagrar una regla de aplicación absoluta e integral respecto de todo el cuerpo de la Ley 18.216. 
no producirá efecto alguno (de carácter excluyente o impeditivo) respecto de la eventual procedencia de las penas sustitutivas que correspondan, pues, si la respectiva condena se encuentra cumplida (en los términos de la ley) y han transcurrido desde dicho hito cinco o diez años (según si se tratare de un simple delito o de un crimen, respectivamente), no es posible oponerse a la consideración del mentado pronóstico favorable respecto del comportamiento futuro del condenado ${ }^{10}$. Cuando menos, por dicha razón. Por ello, no sería propio, por ejemplo, llegar a considerar dicho dato para la apreciación de las denominadas exigencias subjetivas requeridas para la aplicación de los sustitutivos penales que disponen -en general- que "si los antecedentes personales del condenado, su conducta anterior y posterior al hecho punible y la naturaleza, modalidades y móviles determinantes del delito permitieren presumir [concluir] que ...." la medida (pena) es suficiente y no es necesaria la imposición de la originalmente prevista $^{11}$.

Cabe mencionar que una conclusión análoga y a partir de un fundamento similar, fue sostenida por la Corte Suprema en tiempos recientes y aun antes de la promulgación de la Ley 20.603. En concreto -y contra texto expreso- el máximo Tribunal rechazó la idea de que la existencia de condenas precedentes haya constituido un argumento suficiente para negar el acceso al régimen sustitutivo, a partir de una valoración positiva del grado de adaptación social del condenado. Si bien la Corte no presume dicha condición en base al solo transcurso del tiempo, razona en un sentido idéntico al que hemos planteado, conectando dicho antecedente con la afirmación de un pronóstico favorable respecto del comportamiento futuro del condenado ${ }^{12}$.

10 Debemos reconocer que es posible advertir alguna jurisprudencia que no lo ha entendido en la forma señalada. Así, por ejemplo, en la Corte de Apelaciones de Talca, en sentencia de fecha 17 de marzo de 2014, recaída en causa Rol N 91-2014. Corte de Apelaciones de Talca: 17 de marzo de 2014. Rol No 91-2014. “Contra Iván Marcelo Carrasco Morandé”. Disponible en: http://corte.poderjudicial.cl/SITCORTEPORWEB/ [fecha de última visita 20 de marzo de 2015].

11 Dichas exigencias se encuentran previstas, respectivamente, en el art. $4 \mathrm{c}$ ), respecto de la remisión condicional de la pena; en el art. 8 c) respecto de las reclusiones parciales en el art. $11 \mathrm{~b}$ ) respecto de la prestación de servicios en beneficio de la comunidad; en el inciso segundo del art. 15 n. 2), respecto de la libertad vigilada; en el inciso final del art. 15 bis, respecto de la libertad vigilada intensiva;

12 El fallo, de 17 de noviembre de 2011 dictado respecto de un recurso de Casación en el Fondo en causa Rol N 9251-10, modifica la resolución de la Corte de Apelaciones de Santiago que ratificó la condena impuesta por la comisión de nueve delitos de giro doloso de cheques, sancionándolo a la pena única de tres ańos y un día de presidio menor en su grado máximo sin que sea considerado procedente conceder en forma sustitutiva el régimen de libertad vigilada en atención a que el extracto de filiación del condenado da cuenta de registrar dos anotaciones por manejo en estado de ebriedad en los años 1994 y 1996. De manera un tanto extrańa la Corte confirma que efectivamente dichas anotaciones impiden entender satisfecho el requisito de la letra b) del artículo 15 de la ley 18.216, concluyendo que no resulta posible sostener que concurre una infracción de derecho, ratificando de paso 
Ahora bien, como hemos destacado, la exclusión (y la presunción negativa) aparece circunscrita en el tenor de la ley tanto a aquellos casos en que la reiteración o recaida se produce en un periodo de tiempo inferior a los plazos aludidos (supuestos que son interpretados como expresivos de algún grado de tendencia, hábito o disposición concreta a delinquir) como también respecto de quienes, habiendo sido condenados previamente, no han satisfecho las obligaciones asociadas a su condena o, si se prefiere, no "la han cumplido" en los términos de la Ley. En dichos casos, en concreto, no opera el inicio del cómputo de los respectivos plazos que podrían incidir negativamente sobre el efecto excluyente que produce la condena.

El fundamento de esta decisión pareciera asociado en este último caso a la idea de contumacia o rebeldía, dejándose interpretar como una sanción (directa) al desacato o quebrantamiento, en términos similares al supuesto que en doctrina permite diferenciar el tratamiento asignado al concurso real del efecto "agravante" de la reincidencia. Constituye de hecho una consideración negativa que opera, y puede operar, completamente al margen de toda consideración referida al pronóstico y a su relación con el transcurso de un tiempo sin condenas, lo que se evidencia por el hecho de que se trata de casos en que perfectamente se puede constatar un largo periodo sin delito (o condenas) y sin que, a pesar de ello, proceda el acceso al régimen sustitutivo.

Lo relevante a este respecto es que dicha constatación permite advertir que el fundamento esgrimido en el nuevo régimen puede igualmente encontrarse satisfecho cuando concurre alguna forma alternativa de satisfacción de las exigencias de la condena, aun y cuando no supongan el cumplimiento material o efectivo de la pena. Con ello nada parece obstar a que se pueda advertir la concurrencia de las mismas, o incluso, mejores razones para habilitar el acceso al régimen de sustitución, a pesar de que

el que no conduce a una reflexión diversa el que haya transcurrido un largo tiempo desde la última de las condenas, resolviendo que se rechaza el recurso y que la sentencia no es nula. No obstante, una vez seńalado todo lo anterior, consigna que a pesar de ello es legítimo para el Tribunal de Casación intervenir haciendo uso de sus facultades de oficio, y considerando el mérito de los antecedentes, a pesar de las anotaciones, "es un hecho que se trata de un hombre de trabajo, que ha llegado a esta situación patrimonial precisamente como consecuencia de la actividad comercial que desarrollaba, lo cual también resulta consecuente con el informe emitido por el Consejo Técnico del Centro de Reinserción Social Santiago Poniente", agregando que por ello estima que el beneficio de libertad vigilada constituye un instrumento eficaz de resocialización, que por ello se concederá, dejando en tal virtud sin efecto la decisión de primer grado en ese acápite en particular.

Corte Suprema: 17 de noviembre de 2011. Rol No 9251-2010. "Contra Wilfred Rodrigo Arenas Peñaloza”. Disponible en: http://suprema.poderjudicial.cl/SITSUPPORWEB/ [fecha de última visita 20 de marzo de 2015]. Otros ejemplos, de más antigua data, en: Politoff Lifschitz, Sergio; Matus Acuña; Jean Pierre, Ramírez Guzmán, María (2004) Lecciones de Derecho Penal Chileno: Parte General. 2a Edición. Santiago, 613 pp. p. 541. 
se trata de hipótesis que no parecen cubiertas por el tenor expreso del texto legal (debiendo en principio ser excluidas).

Dicho esto, nos proponemos en lo sucesivo revisar los caracteres y fundamentos de estos casos en particular, a fin de confirmar dicha hipótesis, analizando los efectos posibles de atribuir a "la recaida" cuando se han extinguido o modificado las obligaciones que emanan de la condena previamente impuesta por alguna modalidad alternativa al cumplimiento efectivo de la pena, problematizando de esta forma acerca de las razones que pudiere esgrimir el legislador para asignar efectos diversos a ambos grupos de casos (en lo referido al acceso a dichos sustitutivos). No está de más poner de relieve que este ámbito en particular y, en general, todos aquellos que se vinculan a la recaída sancionada que no es constitutiva de reincidencia, han sido generalmente descuidados por la doctrina nacional, a pesar de referirse a situaciones que inciden en forma determinante en la aplicación práctica y diaria del sistema penal, de donde surge en parte el interés y la necesidad de abordarlo en forma particular ${ }^{13}$.

\section{2) CUMPLIMIENTO “DE LA PENA" Y CUMPLIMIENTO “DE LA CONDENA"}

El tenor literal del texto legal pareciera indicar que quienes han sido condenados previamente solo pueden acceder al régimen de sustitución (si concurren los demás requisitos procedentes, incluyendo los plazos mencionados) si hubieren "cumplido" las sanciones impuestas, lo que

13 Hay que tener en cuenta que por sobre lo dicho, y más allá del efecto agravante previsto para ciertos casos de recaída (según las exigencias del artículo $12 \mathrm{~N}^{\circ} 14$ a 16 del Código Penal), el solo hecho de "cometer un delito habiendo cometido otro previamente" produce un conjunto de efectos sustantivos y procesales. Ellos se expresan en la neutralización de una atenuante (la irreprochable conducta anterior del condenado, quien, por ello, ameritará una sanción más aflictiva que la procedente respecto de un "primerizo"), en las exigencias aplicables a la concesión del indulto particular (art. $4^{\circ}$ letras c y e de la Ley 18.050), en la interrupción del plazo de prescripción (conforme dispone el art. 99 del Código Penal), para la fijación del plazo que le permitirá la omisión de sus antecedentes penales (conforme al procedimiento previsto en el Decreto Ley $\mathrm{N}^{\circ} 409$ de 1932) y en el acceso al sistema de reducción de penas en base a comportamiento (conforme al régimen previsto en la Ley 19.856). En el ámbito procesal dichos antecedentes inciden también en la resolución de la prisión preventiva (conforme a lo dispuestos en el art. 140 del Código Procesal Penal) y para la eventual aplicación de la suspensión condicional del procedimiento (art. 237 letra b) del Código Procesal Penal), entre otros. En: Novoa Monreal, Eduardo (2005) Curso de Derecho Penal Chileno. Parte General. Tomo II. 3a Edición. Santiago: Editorial Jurídica de Chile, 477 pp., pp. 92-93, se aprecia un listado de efectos similares (adaptados, eso sí, a la regulación vigente en la época de confección del texto). No obstante, dicho autor yerra al asimilar los presupuestos de dichos efectos a los de la reincidencia, sin advertir que, en todos los casos, se detonan a partir de "condenas anteriores", dato insuficiente para configurar un caso de reincidencia conforme a las exigencias legales. Lo propio sucede en el texto de: Etcheberry (2004) 34, si bien reconoce someramente -y de forma parcial- la diferencia. Igualmente, en forma parcial, Politoff/Matus/Ramírez (2004) 516. 
sugiere una exigencia consistente en que se hayan satisfecho la totalidad de la(s) pena(s) aplicadas en forma efectiva. De esta forma, una interpretación literal -que no parece problemática en este caso- llevaría a sostener que quedan excluidos de dicho estatuto todo aquellos que han extinguido su responsabilidad en base a mecanismos alternativos y diversos, aun y cuando lo hubieren hecho antes de cinco o diez ańos, según se trate, respecto de la fecha de comisión del nuevo delito.

Lo problemático de asumir esta lectura literal, estricta o restrictiva, es que lo normal será que el conjunto de personas descrito en estos últimos supuestos suelen ofrecer condiciones de (re)inserción social equivalentes o incluso superiores a las de quienes han dado cumplimiento efectivo a la totalidad de la pena originalmente impuesta, reforzando con ello el fundamento que habilita a levantar "la exclusión" en el acceso a sustitutivos. Así, quienes han satisfecho una pena sustitutiva o han sido beneficiados con un indulto parcial y quienes se desempeñan en la sociedad habiendo ya prescrito la pena que se le hubiere sido impuesta largos años atrás, constituyen ejemplos que suelen ofrecer buenas perspectivas de futuro en lo referido a un potencial comportamiento delictual, concurriendo por ello buenas razones para habilitar el régimen de sustitutivos a su respecto.

Los puntos relevantes radican a nuestro juicio en advertir que, en todos estos casos, se trata de condenados que han extinguido igualmente su responsabilidad penal en base a la aplicación de mecanismos que gozan de pleno reconocimiento legal (es decir, que no han operado al margen del derecho) y que, además, pueden afirmar que han cumplido plenamente con su condena sin perjuicio de que no han satisfecho o ejecutado "la pena impuesta". En cuanto la primera constatación no parece problemática (pues, el análisis se limita a casos que gozan de reconocimiento legal) resulta determinante analizar las diferencias que pudieren existir entre el hito que representa el cumplimiento de una pena y el que subyace al cumplimiento de una condena, a objeto de verificar, a partir de ello, si la distinción ofrece relevancia para justificar una interpretación restrictiva del texto legal, conforme a los fundamentos que la inspiran.

\section{1.) NECESIDAD DE DISTINGUIR EL CUMPLIMIENTO DE “LA PENA” Y CUMPLIMIENTO DE “LA CONDENA”}

A nivel lingüístico existe una clara diferencia entre afirmar que se ha cumplido con la pena y que se ha cumplido con la condena. El primer concepto se vincula a un determinado y concreto régimen de restricción de derechos (una pena determinada) mientras que el segundo se concentra más bien en el continente de dicho efecto, esto es, en la obligación que 
recae sobre el condenado de satisfacer una determinada restricción de derechos. Constituyen por ello, técnicamente, referentes diversos ${ }^{14}$.

Ello queda claro si se revisan los efectos de la comisión de un delito en forma secuencial pues lo que nace del delito no es sino el deber de responder conforme a derecho (responsabilidad penal), efecto que incluye la obligación de satisfacer una determinada forma de restricción de la autonomía personal (la pena), entre otras consecuencias ${ }^{15}$. La pena no es entonces un efecto directo del delito (en cuanto consecuencia de la responsabilidad penal que emana de su comisión ${ }^{16}$ ) sino que lo es la obligación de satisfacer una condena penal ${ }^{17}$.

Ahora bien, se trata de una "carga" (de llevar a cabo una pena) que evidentemente se extingue en caso de cumplimiento satisfactorio de sus contenidos, pero que también puede cesar (o, si prefiere, "extinguirse") a raíz de contingencias que tengan la virtud de alterar su sentido originario (esto es, el significado que proponen para la intervención penal), debiendo para ello haber sido valoradas a dichos efectos por el legislador. Entre ellas se contemplan en el ordenamiento vigente en Chile: la muerte del condenado y el perdón del ofendido (siempre que se produzcan después de la declaración de la responsabilidad), la prescripción de la pena y el propio cumplimiento satisfactorio de cualquiera de las penas sustitutivas previstas en la Ley $18.216^{18}$ o de la prestación de servicios en beneficio

14 A pesar de ello constituyen términos que suelen ser utilizados en los textos legales (jurisprudenciales y doctrinarios) en forma indistinta y aleatoria.

15 En efecto, la obligación de dar cumplimiento a la pena es, técnicamente, una consecuencia (entre otras) de la responsabilidad que emana de la comisión de cualquier delito (responsabilidad penal) y que se torna exigible (en general) a partir de su declaración judicial en una sentencia condenatoria (en el mismo sentido: ETCHeberry (2004) 9, más allá que luego defina la noción de responsabilidad penal a partir de la pena y no del delito). Además de ello, se pueden considerar como efectos de la responsabilidad penal: i) la imposición de consecuencias accesorias (incluyendo la propia inhabilitación para acceder a los sustitutivos); ii) los efectos o consecuencias comunes a todo delito; y iii) los efectos propiamente civiles que emanan del mismo. Próximo, si bien en términos más genéricos: Rodríguez Collao, Luis (2011) "Naturaleza y fundamento de las circunstancias modificatorias de la responsabilidad criminal”. Revista de Derecho de la Pontificia Universidad Católica de Valparaíso, Volumen XXXVI, pp. 397-428, p. 399 y 402 (con cita a Jiménez de Asúa), más allá que luego (en p. 405) parezca sostener un criterio diverso, declarando que no hay en estos casos una obligación referida a cumplir las penas, sino una sujeción respecto del Estado.

16 En este sentido se pronuncia la opinión dominante en Chile, calificada como "extra sistemática” por Rodríguez (2011) 400 y 403. Este mismo autor expone asimismo una síntesis de los diversos sentidos de la expresión (responsabilidad penal) en p. 400 y ss. Con respecto a esto último: De la Fuente Hulaud, Felipe (1990) "Sobre el concepto de responsabilidad criminal en nuestro Código Penal". Revista de Derecho de la Pontificia Universidad Católica de Valparaíso, Volumen XIII, pp. 113-123, pp. 113 y ss.

17 En un sentido materialmente análogo RodRíguez (2011) 399.

18 Se consideran, específicamente, la remisión condicional de la pena, la reclusión parcial, la prestación de servicios en beneficio de la comunidad, la libertad vigilada y la libertad vigilada intensiva. Asimismo, se debe agregar la expulsión del país, que permite sustituir determinadas condenas impuestas a extranjeros. 
de la comunidad sustitutiva de la multa. En todos esos casos se puede afirmar concretamente que el condenado ha cumplido con la obligación impuesta en su condena, con total independencia de que para ello no haya satisfecho la pena determinada inicialmente en dicho instrumento.

Estas situaciones presentan particularidades comunes relevantes de tener en cuenta a los efectos que ahora nos ocupan. En primer lugar, por el hecho de que cada una de ellas tiene la virtud de hacer cesar la obligación de cumplir una pena, efecto que se predica de todas ellas en igualdad de condiciones. Lo segundo es que no se trata de casos en los que se ponga fin a la totalidad de los efectos de la responsabilidad penal, pues, al igual a como sucede en caso de cumplimiento efectivo de la o las penas impuestas, sobreviven a ella los denominados efectos civiles provenientes del delito y todos aquellos que se encuentran asociados a la propia condición de penado (inhabilidades administrativas, políticas y algunas civiles, el efecto admonitorio en casos de nueva condena y el registro del prontuario penal y de ADN criminal) ${ }^{19}$. Estos "otros efectos" solo se verían afectados si se constatan eventos que extinguen (directamente) la propia "responsabilidad penal" 20 o cuando ocurren otros a los que se reconoce la virtud de incidir específicamente sobre las restricciones asociadas al "carácter de condenado" 21 , mientras que los efectos propiamente civiles suelen correr por cuerda separada (según sostiene en forma dominante la doctrina). Con ello resulta posible afirmar que los efectos específicos que ofrecen dichas situaciones son plenamente equivalentes a los que ofrece el cumplimiento efectivo de la(s) pena(s) impuestas, sin que se trate, en ambos casos, de formas de satisfacción que afecten o incidan en el conjunto de todas las consecuencias asociadas a la responsabilidad penal.

Lo tercero, es que se trata de los únicos casos en que se puede afirmar directamente que se ha "cumplido" o "satisfecho" "la condena", a pesar de que, según advertimos, no se trata de casos que incidan en la totalidad de los efectos que emanan de la responsabilidad penal (que por ello se podrían entender "incumplidos")22. Ello sucede pues la idea de cumplimien-

Se aprecia en forma parcial en Politoff/Matus/Ramirez (2004) 569, si bien la coincidencia con el criterio de fondo que hemos sustentado en el texto es total. En un sentido equivalente Rodríguez (2011) 399, con cita a Zaffaroni, destaca la multiplicidad de efectos emanados de la responsabilidad penal, sin ofrecer en todo caso una sistematización como la sugerida en el texto.

Así sucede en los casos de "amnistía" cuando tiene lugar después de que se ha emitido la condena y en los casos en que se produce la "derogación del delito", y que tienen como efecto propio el hacer desaparecer todos los vestigios que puedan asociarse al carácter delictivo del hecho.

21 Así sucede con la prescripción de la reincidencia (art. 104 del Código Penal), la eliminación de antecedentes penales (Decreto Ley 409 de 1932 y Decreto Supremo No 64 de 1960) y la rehabilitación de derechos políticos (art. 17 inciso final de la CP).

22 Se podría controvertir la posibilidad de "quebrantamiento" de las consecuencias accesorias en aquellos casos en que su contenido se identifica con las penas de interdicción. Lo 
to no resulta aplicable a las demás consecuencias penales del delito, en cuanto se trata de restricciones que simplemente se "sufren" o "padecen", pero que no pueden "cumplirse" o "incumplirse" 23 . De esta forma, resulta posible sostener que toda valoración relativa al "cumplimiento" o "satisfacción" de la responsabilidad penal se encuentra circunscrita al campo de las obligaciones asociadas a la ejecución (directa o indirecta) de las penas, en sentido estricto.

Ahora bien, existen también otro tipo de situaciones (de origen igualmente contingente) cuya valoración por parte del legislador impide que se dé cumplimiento efectivo a la pena impuesta, pero esta vez en cuanto producen como efecto concreto una modificación en las condiciones que subyacen a dicha obligación. Entre ellos se cuenta el indulto, la concesión de las penas sustitutivas previstas en la Ley $18.216^{24}$ o de la prestación de servicios en beneficio de la comunidad en reemplazo de la multa $^{25}$; la modificación legal de la pena en favor del reo, la reducción de condena por la observancia de un comportamiento sobresaliente durante su cumplimiento ${ }^{26}$ y el abono del tiempo cumplido en prisión preventi$\mathrm{va}^{27}$. Si bien el efecto de dichas circunstancias no se encuentra vinculado de forma directa con el evento que hemos sindicado como cumplimiento de la condena (que se producirá en esos mismos casos acorde a las reglas generales), su concurrencia produce una "modificación" en el hito, mo-

relevante sin embargo es que su padecimiento es más bien expresión de una incapacitación jurídica o formal que incide por ello en la legalidad de lo ejecutado, efecto que no puede predicarse de las condenas (propiamente tales) a una "pena" (principal) de inhabilitación.

23 Evidentemente no nos referimos con ello a la voluntariedad de su cumplimiento o satisfacción pues parece evidente el que es connatural a la pena el que puede ser impuesta coactivamente contra la voluntad del destinatario. En este sentido se ha llegado a sostener que el condenado no está "obligado" sino "sujeto" a la "pena". Al respecto Rodríguez (2011) 405 .

24 Dicha decisión produce materialmente el efecto de modificar el contenido de la sanción que se va a cumplir toda vez que el efecto concreto que produce su ejecución es equivalente a su cumplimiento efectivo. Se demuestra en cuanto la revocación durante el periodo destinado a su cumplimiento no hace renacer la obligación de dar total cumplimiento a la pena originalmente puesta, sino a la parte de ella que hubiere quedado sin cumplir, descontándose de la pena original el tiempo que se hubiere cumplido efectivamente la respectiva pena sustitutiva (véase el art. 26 de la Ley 18.216). Conforme a la regulación previa a la modificación introducida por la Ley 20.603 a la Ley 18.216 este efecto solo podría predicarse de la reclusión nocturna. De ahí que haya sido acertado que se la calificara como una verdadera pena sustitutiva. En este sentido: Politoff/Matus/Ramírez (2004) 546.

25 Art. 49 bis del Código Penal.

26 Ley $\mathrm{N}^{\mathrm{a}} 19.856$

27 El indulto sobre condenas accesorias (salvo que fuere total) y la omisión de antecedentes penales producen estos mismos resultados sobre los efectos de la responsabilidad penal que se encuentran asociados a la condición de condenado, en cuanto su concurrencia altera el contenido original de las restricciones asociadas. 
mento o condiciones en que ello sucederá, siendo relevante por ello tenerlas en cuenta a estos efectos ${ }^{28}$.

Un buen ejemplo para demostrarlo lo proporciona el contenido de las propias penas sustitutivas previstas en la Ley 18.216. La satisfacción parcial de cualquier de ellas (en casos de incumplimiento grave o reiterado del régimen en curso) no genera más efectos que el haber producido una modificación igualmente parcial en el contenido de la obligación inicial del penado (prevista en la condena), quien deberá cumplir el saldo de pena acorde a los caracteres de aquella que hubiere sido originalmente impuesta ${ }^{29}$. En dicho caso, se extinguirá la obligación por el cumplimiento (efectivo) parcial de la pena sustitutiva que se hubiere satisfecho sumado al cumplimiento (efectivo) parcial de la pena original. El caso en que se proceda a su cumplimiento (efectivo) total detonará la satisfacción de la condena, siendo evidente que es dicha causal (el cumplimiento efectivo) la que operaría como mecanismo de extinción de la responsabilidad. Lo propio acontece con el indulto, por ejemplo, en casos de conmutación, siendo la satisfacción de la "nueva pena impuesta" lo que detonará dicho efecto extintivo. Y lo mismo pasa (si bien de forma más desapercibida) con el indulto parcial que incide en la totalidad del tiempo que reste al beneficiario para cumplir con su pena, caso en el que la concesión de esta gracia produce el efecto de "aproximar dicho momento en el tiempo", pudiendo inclusive llegar a transformarlo en un efecto inmediato.

Nada impide, de hecho, que en esos casos pueda llegar a operar otra forma de extinción, como sucedería ante la ocurrencia de la muerte del condenado mientras se cumple la reclusión nocturna, la pena conmutada, etc., lo que confirma el que dicho efecto (el "cumplimiento") se encuentra en dichos casos confiado al régimen que proponen las reglas generales.

A estas alturas conviene recordar que una lectura literal de los términos de la ley llevaría necesariamente a considerar que todos estos casos se encuentran excluidos de la eventual aplicabilidad de las penas sustitutivas previstas en la Ley 18.216, en cuanto en ninguno de ellos se puede afirmar que el condenado "ha dado cumplimiento" efectivo "a la pena impues$t a$ " en la sentencia condenatoria. Se puede sin embargo advertir, en todos ellos, que se ha "extinguido la responsabilidad penal" y que se ha cumplido con las obligaciones (posibles de cumplir o satisfacer) que emanan de la condena, al igual a como sucede en los casos de cumplimiento efectivo de la pena.

28 Politoff/Matus/Ramírez (2004) 569, donde se incluyen algunos de dichos casos dentro de la causal de cumplimiento efectivo de la pena.

29 Arts. 25 y 26 de la Ley 18.216. Véase también el art. 31, respecto del abono aplicable a los casos en que el trabajo en beneficio de la comunidad sustituye a una pena privativa de libertad. 


\section{2.) SignifiCAdO O SENTIDO DEL “CUMPLIMIENTO DE LA PENA"}

Con base al desarrollo expuesto, consideramos que el legislador se ha inclinado en favor de exigir la satisfacción o cumplimiento del contenido de la condena para habilitar al cómputo del plazo que permitirá volver a tener acceso al régimen de sustitutivos, con total independencia de que se haya dado o no satisfacción material a la pena originalmente impuesta.

El punto es que, en el marco de los objetivos asociados a la reinserción de quien ya ha sido condenado, en nada aporta la diferencia que existe entre quienes han cumplido efectivamente con (todo o parte de) dicha condena y quienes han extinguido su responsabilidad por condiciones diversas, pues en todos estos casos lo relevante es verificar si, a partir del hecho delictivo, los condenados pueden dar cuenta de condiciones que reducen las probabilidades de una recaída en términos similares o equivalentes a los de quienes carecen de antecedentes prontuariales. En este contexto la ejecución material o efectiva de la pena no parece aportar ningún elemento relevante de considerar, pues el tiempo transcurrido sin condena ofrecerá, siempre, el mismo contenido: una revalorización del pronóstico futuro a partir de la experiencia previa.

Pero además, debemos tener en cuenta que la ejecución de la pena pareciera incluso incidir en términos negativos en dicho pronóstico, haciendo más relevante el transcurso del tiempo o la existencia de instancias de apoyo postcondena que ayuden a minimizar los efectos indirectos que provienen del padecimiento de la condena. Si bien no parece discutible que en nuestro régimen legal la reinserción constituye uno de los objetivos de la ejecución penal ${ }^{30}$, pudiendo por ello confiar en que el paso por el control penal efectivo incorporará en el condenado elementos que favorecerán un comportamiento futuro alejado del marco de lo delictivo (prevención especial positiva), no parece posible sostener realmente que ello haría aconsejable la satisfacción material de la pena bajo la pretensión de que a partir de ello se podría esperar un incremento en las probabilidades de conseguir el objetivo esperado. Lo relevante es que se puede afirmar con el mismo nivel de seguridad que el carácter aflictivo de la condena influye (por definición) en sentido inverso, en cuanto conlleva restricciones a la autonomía que minimizan el desarrollo de la socialidad. Y es que la cárcel (por ejemplo) no puede recrear lo que es la vida en libertad, siendo posible sostener incluso que la ejecución de la pena (directamente) desocializa.

30 Al respecto: Carnevali Rodríguez, Raúl; Maldonado Fuentes, Francisco (2013) "El tratamiento penitenciario en Chile". En Arozena, Gustavo (director): El tratamiento penitenciario. resocialización del delincuente, Buenos Aires: Editorial Hammurabi, 209 pp., p. 120. 
Esta perspectiva aconseja el uso de mecanismos menos restrictivos $y$, de ser posible, renunciar al uso de la sanción penal, si ello ofrece un mejor punto de equilibrio entre estas dos dimensiones de la prevención especial positiva. Si esto es así, resulta posible suponer que quienes han incurrido en un delito y no reciben los efectos concretos del sistema penal o reciben solo una parte de los mismos, presentan una posición (al menos) equivalente o inclusive superior a la de quienes, habiendo cumplido la pena, se enfrentan nuevamente al desarrollo de la vida en libertad. De hecho, el pronóstico pareciera más certero respecto de quienes han modificado el contenido de ejecución original de dicha condena, ya sea por haberla sustituido por un régimen de libertad condicional (conforme dispone el Decreto Ley 321 de 1932), por haber reducido su pena por la observancia de un comportamiento sobresaliente durante su cumplimiento (conforme al régimen previsto en la Ley 19.856). Con ello se reafirma que la ejecución material de la pena no propone un elemento de juicio que pueda ser considerado decisivo a este respecto, sino al contrario: existen buenas razones para sostener un mejor pronóstico de futuro en quienes han accedido a formas alternativas de ejecución en relación a quienes han dado satisfacción íntegra y cabal a la pena impuesta (pues, de hecho, se trata de condenados que no habrán accedido a los regímenes de libertad condicional, de reducción de condenas, etc.). A ello agrega que el régimen de apoyo o tratamiento post penitenciario en Chile es prácticamente inexistente, reafirmando la corrección de esta apreciación.

Casi resulta innecesario señalar que estas apreciaciones se replican de manera idéntica respecto de quienes hubieren cumplido total o parcialmente su condena en base a alguno de los sustitutivos previstos en la Ley 18.216, en atención a que las propias exigencias que permiten su aplicación conllevan (por definición) la afirmación previa de una apreciación equivalente (y positiva) sobre el potencial comportamiento delictual futuro del condenado. De hecho, resulta indiciario a este respecto que la sola imposición de alguna de las penas sustitutivas conlleve la inmediata omisión del dato de la condena en las certificaciones correspondientes al prontuario penal ${ }^{31}$, previéndose además su virtual eliminación en caso de cumplimiento satisfactorio $^{32}$. Lo dicho se puede interpretar como una

31 En términos prácticos, ello aplica a los certificado emitidos para fines particulares.

32 A este respecto conviene aclarar que el cumplimiento satisfactorio de cualquiera de las penas sustitutivas previstas en la Ley 18.216 no provoca la eliminación de los antecedentes prontuariales asociados a la respectiva condena, a pesar de que el texto del art. 38 de la Ley 18.216 parezca indicar lo contrario. Lo que hace la disposición citada es ofrecer un tratamiento privilegiado respecto de la comunicación que es posible realizar respecto de los antecedentes penales de quienes hubieren sido beneficiados con alguna de las penas sustitutivas. Si bien el legislador declara que dicho antecedente "tendrá mérito suficiente para la eliminación definitiva, para todos los efectos legales y administrativos, de tales antecedentes prontuariales" (Art. 38 de la Ley 18.216), el inciso final de la citada disposición determina 
opción del legislador en favor de la reinserción de quienes acceden a dichas sanciones, cuya justificación necesariamente comparte el fundamento que justifica su previsión, y que coincide con una valoración personal semejante a la antes señalada.

Debemos mencionar además que no es lógico suponer que tras esta asimilación se esconda un tratamiento discriminatorio, en cuanto permitiría que quienes han logrado sortear eficazmente el cumplimiento de la pena se vean beneficiados en igualdad de condiciones respecto a quienes, por el contrario, han debido soportar las cargas de la ejecución. A este respecto lo relevante es que todos los casos en que se extingue la obligación de cumplir una pena se encuentran amparados por una valoración legal, constituyendo situaciones en las que el propio legislador (o el constituyente) ha previsto que la ejecución material de la pena impuesta originalmente es innecesaria, inconveniente o simplemente inútil, a partir de valoraciones análogas a las que subyacen a la creación de un delito y la asignación de su pena. De esta forma, si se trata de un juicio de legalidad o de legitimidad, ambas situaciones se muestran como equivalentes.

Tampoco se puede sostener que su aplicación a dichos casos materializaría una especie de incentivo indeseable. Ello sería absurdo, toda vez que los desincentivos para dar cumplimiento a la pena emanan directamente, y en forma suficiente, de sus propios contenidos, lo que hace que cualquier otro potencial beneficio asociado a su no cumplimiento se torne (del todo) superfluo.

Lo dicho resulta especialmente relevante en el análisis de los casos en que opera la prescripción de la pena, pues constituye la hipótesis que más se aleja de la exigencia de cumplimiento material de la condena ( $y$, con seguridad, de la idea de cumplimiento de la pena) toda vez que su efecto natural es precisamente evitar que se materialicen las obligaciones asocia-

(como excepción) la supervivencia de dichos registros a efectos de las inhabilidades administrativas y la valoración de la reincidencia, lo que en términos prácticos resulta incompatible con la "efectiva eliminación" anunciada previamente. Con ello, una interpretación sistemática obliga a entender que el efecto real que emana del cumplimiento satisfactorio de dichas medidas se limita entonces a una mayor extensión del marco de la omisión de antecedentes, debiendo solo considerarse dicho registro en las certificaciones dirigidas a instancias donde se deban hacer efectivos los efectos recién mencionados. La jurisprudencia administrativa (mediante dictámenes de la Contraloría General de la República) ha confirmado este criterio de manera reiterada (en términos vinculantes para el Servicio de Registro Civil), si bien respecto del texto de la regulación precedente (idéntico en contenido). Ver dictámenes 16.593 ( del año 2004), 36.773 ( del año 2006), 7.426 (del año 2008), 64.821 (del año 2009) y 30.442 (del año 2010). En el ámbito judicial la jurisprudencia también lo ha ratificado, como se puede apreciar en sentencia de la Corte de Apelaciones de Temuco Rol 486-07, de 2 de mayo de 2007. De esta forma, la única forma de proceder a una eliminación real consiste por ello en recurrir al régimen general Previsto en el Decreto Ley 409 de 1932 o en los casos reglados en el Decreto Supremo N 64 de 1960, con lo cual, el caso de cumplimiento de las penas sustitutivas produce, a los efectos que nos interesan, las mismas consecuencias que cualquier otra forma de cumplimiento de la condena. 
das a la misma. A dicho respecto hay que tener en cuenta en primer lugar que no deja de ser una forma de satisfacer las obligaciones que impone la condena y (con ello) de ponerle término. No hay que olvidar que lo relevante es que la obligación que emana de la condena se extinga o cese, con independencia de si ello deviene a partir de la ejecución material de la condena original, de partes de la misma, de otra que la sustituye o, finalmente, de que se ha estimado innecesario o inconveniente para alcanzar los fines que la motivan.

El sentido de su imposición (y con ello el que puede predicarse de la obligación que ello conlleva) se basa en el contraestímulo que produce la pena (su amenaza concreta), tanto para el infractor como para la sociedad, efecto del que además se extrae un mensaje de seguridad de carácter general (el delito no se repetirá). La obligación que lleva a la ejecución de la pena se basa por ello en la estricta necesidad que existe en los intereses públicos de alcanzar dichos objetivos, necesidad que no emana solo de los caracteres del delito. Concurren a configurarla (y, en su caso, a hacerla desaparecer) un conjunto de factores presentes en el sujeto, en las valoraciones sociales y en el contexto de aplicación, que pueden modificar la percepción abstracta y general que produce la exclusiva consideración del ilícito.

De ahí por ejemplo que entendamos satisfecha dicha necesidad en casos de amnistía o en los casos en que parece aconsejable obviar la ejecución material de la pena (remisión condicional de la pena, etc.) por existir motivos que permiten sustentar un mecanismo menos invasivo y más efectivo para alcanzar dichas necesidades, ejemplos (todos) en los que se cumple con los objetivos de la condena penal en forma alternativa a la ejecución de su contenido original.

Como se verá a partir de estos mismos ejemplos, la compleja evaluación sobre la necesidad de la pena no solo se produce a la hora de fijar la condena inicial y las obligaciones que conlleva (p. ej., cuando se decide remitir la pena en forma condicionada) sino también a través del tiempo (p.ej. en la propia revocación de dicha remisión o en la amnistía), pues las condiciones bajo las cuales se desarrolla la ejecución también inciden inevitablemente en la actualización de dicha valoración (la necesidad de la pena). Por ello es que en ninguno de los casos antes mencionados llame la atención que se altere el contenido original de la obligación que emana de la condena, concurriendo siempre algún elemento relativo a la valoración de la necesidad de la pena (para el cumplimiento de sus objetivos) que lo justifique. Nada debiera por ello extrañar si estos mismos factores aconsejan que en algún momento renunciemos a la imposición de toda pena para satisfacer dichos intereses. Así sucede en los casos ya mencionados, 
como la amnistía o la remisión condicional de la pena que hubiere sido cumplida satisfactoriamente, y también en la prescripción ${ }^{33}$.

Podemos entonces asumir que no hay contradicción alguna entre el efecto de la prescripción de la pena y el hecho que podamos considerar satisfechos los objetivos de la condena, que, en este caso (como en los recién mencionados) se materializa a través de una forma de extinción de la obligación de cumplir la pena que, en general, no supone la ejecución de una consecuencia alternativa.

Debemos recalcar finalmente que concurre además en este caso en particular una razón que potencia la consideración de la prescripción a efectos que nos ocupan. En cuanto el acceso al régimen de sustitutivos penales se basa y orienta (a la vez) a objetivos asociados a la inserción social del condenado es altamente relevante que, al menos a nivel normativo (que es en el que se mueve el sistema penal), la prescripción evidencia de manera concreta que en todo el tiempo transcurrido el condenado rebelde no ha cometido un nuevo delito. Si así fuera, operaría su interrupción y no produciría efectos jurídicos, debiendo comenzar nuevamente el cómputo $^{34}$. Se trata de una valoración idéntica a la que justifica la modificación introducida por la Ley 20.603 al régimen de exclusión previsto en la Ley 18.216 que priva de acceso a los sustitutivos en atención a la presencia de condenas previas y que lleva a considerar que la constatación de un lapso sin que se haya cometido un delito permite sostener un pronóstico de socialidad futura favorable, obviando el dato que aporta su comisión. Constituye un antecedente que, a este respecto, coloca a esta institución en una posición muy superior a la que ofrece la propia ejecución de la

33 Como indica GARrido (2007) 388: "La necesidad de pena va disminuyendo hasta diluirse en pro de la justicia y de la paz social. La alarma e inquietud producidas por el delito se acaban, por otro lado, el delincuente no ha sido sancionado y sin embargo no ha incurrido en reiteración de comportamientos análogos; esto significaría que se ha reinsertado en el ámbito social, lo que hace aconsejable no modificar ese estado de cosas". En el mismo sentido: CuRY (2005) 798. Algunos autores se inclinan más bien por fortalecer el papel que cumple a este respecto la seguridad jurídica (la necesidad de estabilizar formalmente las relaciones sociales) y el aumento en la probabilidad de un error judicial (por la dilución que experimentan los antecedentes de prueba o convicción), entendiendo de paso que ello contradice los objetivos recién mencionados. En este sentido: GuzMán DÁlbora, José Luis (2002) “Comentario al Título V del Libro I”. En Politoff Lifschitz, Sergio; Ortiz Quiroga, Luis (directores): Texto y Comentario del Código Penal Chileno. Tomo I Libro Primero - Parte General. Artículos $1^{\circ}$ al 105. Santiago: Editorial Jurídica de Chile, 493 pp., p. 461, y: NOVOA (2005) 402. Dichos autores olvidan sin embargo que la estabilidad que supone la seguridad jurídica y la condena son también parte de los objetivos que pretende el sistema penal. Al respecto: Hassemer, Winfried (1999) “¿Por qué y con qué fin se aplican las penas? Sentido y fin de la sanción penal”. En Hassemer, Winfried: Persona, mundo y responsabilidad. Valencia: Editorial Tirant lo Blanch, 294 pp., p. 206. Con claridad también en: Piña Rochefort, Juan Ignacio (2005) "Algunas consideraciones acerca de la (auto) legitimación del derecho penal”. En Gómez-Jara Díez, Carlos (editor): Teoría de sistemas y derecho penal. Fundamentos y posibilidades de aplicación. Granada: Editorial Comares, 558 pp., p. 265.

Según dispone el art. 96 del CP. 
condena, cuyo término (por ejemplo en casos de cumplimiento total y efectivo) plantea mas bien una razonable duda sobre la probabilidad de recaída futura ${ }^{35}$, haciendo aun más razonable a nivel material apreciar la concurrencia de los fundamentos tenidos en cuenta para disponer la anulación de dicho efecto excluyente. Hay que tener en cuenta, además, que el efecto asociado al tiempo concurre en estos casos en forma reforzada, considerando que al plazo sin condenas que habilita a la prescripción se suma aquel que exige la Ley 18.216.

\section{3) EXCLUSIONES CENTRADAS EN LA REVALORIZACIÓN DEL HECHO}

Además de lo señalado conviene tener en cuenta que también se debe obviar la limitación prevista para los reiterantes, pero por razones diversas, en aquellos casos en que se extingue directamente la propia responsabilidad penal en general y solo no alguna o algunas de sus consecuencias. En estas situaciones es la propia amplitud de los efectos previstos para dichas situaciones lo que afecta directamente a la supervivencia de la correspondiente condena a los efectos de su consideración en un hecho posterior. En particular, se trata de hitos o situaciones que inciden sobre la totalidad de las consecuencias que pueden asociarse a la comisión del delito, incluyendo la obligación de cumplir una pena y las consecuencias asociadas a la condición de condenado ${ }^{36}$. Se afecta con ello el propio significado del evento constitutivo del delito (ya cometido, en estos casos) en términos absolutos o en relación a la actualidad de su calificación jurídica, anulando los efectos expresivos propios de la condena penal, consecuencia que se extiende por esta misma razón a todos los efectos asociados a su existencia jurídica (incluyendo el que nos ocupa). De ahí que, conforme a su respectivo fundamento, se trate de hipótesis en las que debería eliminarse automáticamente la respectiva anotación prontuarial emanada de dichas condenas, efecto que por ello debiera

35 Debe considerarse además que si hay cumplimiento efectivo y total se tratará de condenados que no habrán accedido siquiera al régimen de libertad condicional.

36 Valga a este respecto lo sostenido previamente respecto a los efectos (propiamente) civiles que emanan de la responsabilidad penal pues la revalorización que ellos suponen no se extiende necesariamente al contenido de la ilicitud general, alcanzando de seguro solo a la de naturaleza penal (sobre esta distinción: Mir Puig, Santiago (2007) Derecho Penal. Parte General. $7^{\text {a }}$ Edición. Barcelona: Editorial Reppetor, 781 pp., p. 165). En este mismo sentido Cury (2005) 791, mencionando su origen ilícito (lo que aplica a las indemnizaciones) y el derecho de propiedad (los derechos adquiridos). Asimismo Etcheberry (2004) 250; Guzmán (2002) 450; Novoa (2005) 395; Politoff/Matus/Ramírez (2004) 570. 
operar de oficio, afectando además, por su propia naturaleza, toda eventual consideración posterior ${ }^{37}$.

El caso más claro se produce cuando el legislador decide derogar una disposición que tipifica y penaliza un determinado comportamiento, pues, por efecto de la aplicación del principio de retroactividad de las leyes penales favorables al reo no solo deberá cesar la pena que se estuviere cumpliendo, o la que debiese llegar a cumplirse, sino que además deberán dejarse sin efecto las demás consecuencias asociadas a su comisión, exceptuando naturalmente aquellas que hayan generado derechos adquiridos. Lo que sucede es que el legislador ha propuesto directamente una revalorización del hecho, de modo que no existe motivo alguno para darle a su comisión, incluso histórica o pretérita, un tratamiento equivalente al que amerita una condena penal. Ello, por la misma razón, debiera también afectar a la propia posibilidad de considerar que dicho hecho puede llegar a generar efectos de naturaleza penal y que el hechor deba ser considerado como un infractor de la ley penal. Con ello, al desaparecer el fundamento, deban también desaparecer todas sus consecuencias ${ }^{38}$.

37 Constituyen de hecho casos equivalentes a aquellos en que la concurrencia de determinadas situaciones impide directamente que se llegue a declarar la responsabilidad penal y que, por lógica, no ofrecen problema alguno en referencia a la temática que nos ocupa. Así sucede con la prescripción de la acción penal, con la amnistía y con el perdón del ofendido (cuando procede), en aquellos casos en que concurren antes de la dictación de la sentencia; También, si bien tampoco resulta relevante a nuestros efectos, cuando acaece la muerte del presunto responsable antes de la respectiva sentencia condenatoria. Opera igualmente, al margen del efecto asociado a la presunción de inocencia, cuando se aplica el principio de oportunidad, la suspensión condicional del procedimiento (cuando se ha cumplido satisfactoriamente) y el acuerdo reparatorio. En todos estos casos los efectos asociados a su ocurrencia suelen ser automáticos, por cuanto impiden la propia declaración de la responsabilidad penal (que, por ello, no se puede afirmar). Una opinión diversa se puede consultar en: GarRIDo (2007) 369 y ss.

38 Es evidente que ello no puede alcanzar el marco de las obligaciones ejecutadas bajo el amparo de la reglamentación vigente al momento de imponerlas. Ello no solo incide en las indemnizaciones pagadas sino también en la condena cumplida pues en ambos casos se trató de efectos legítimamente reclamados. La ley chilena también exceptúa a las inhabilidades (art.18 inciso final del Código Penal) lo que ha sido interpretado por la doctrina como una referencia a ciertos efectos civiles y administrativos asociados al delito (CuRY (2005) 231; Etcheberry (2004) 147) constituyendo una excepción al efecto absoluto que debiera extraerse de la derogación en cuanto permitiría la supervivencia de consecuencias que tienen su fundamento en la condición de condenado (como las inhabilidades "civiles" asociadas al servicio público o militar). La explicación de su consideración formal se encuentra en la progresión histórica que ha tenido en Chile el reconocimiento de los efectos que emanan de la revalorización que supone la derogación de un delito pues, hasta el año 1972, se entendió que las reformas de este tipo no incidían en modo alguno en las condenas ejecutoriadas, en cuanto se sobrevaloraba el efecto de cosa juzgada por sobre el que emana de los fundamentos de la derogación (Novoa (2005) 189). La Ley introduce en dicho año los incisos finales del art. 18 del Código Penal, avanzando en el reconocimiento de los efectos que naturalmente debieran asociarse a una derogación. En la actualidad, parece claro que dicho reconocimiento debe ser total, extendiéndose incluso a las inhabilidades mencionadas, y así se desprende de la amplitud que plantea el texto constitucional que regula la materia (art. 19 
La amnistía también propone una revalorización del hecho ${ }^{39}$, o, si se prefiere, una anulación de la desvalorización que representa el delito que ha motivado la condena. En este caso se trata de una decisión legislativa de carácter parcial (no permanente) en tanto se fundamenta exclusivamente en los caracteres presentes en un contexto en particular. Lo normal será que constituya el fruto de una decisión político criminal, tras la cual el legislador expresa su convicción de que los caracteres concretos de los casos que se pretenden regular en forma especial quedarían mejor resueltos si se renuncia en ellos a la intervención penal, por consideraciones que normalmente se encuentran asociadas a la mejor obtención de niveles satisfactorios de paz social ${ }^{40}$. Constituye por ello una especie de ley derogatoria ad-hoc ${ }^{41}$, que produce efectos similares o equivalentes a una despenalización, acotados, eso si, al marco contextual donde dicha valoración presenta sentido. Amnistía significa amnesis (olvido) contenido que se expresa tras la idea de que el legislador procede a "borrar el delito" 42 , debiendo (en consecuencia) extinguirse todos los efectos que puedan encontrarse asociados al mismo o al hecho de su comisión ${ }^{43}$.

No es extraño entonces que el ordenamiento vigente disponga para este caso en particular un mecanismo que habilite a la total supresión de las anotaciones prontuariales correspondientes al delito (o delitos) amnistiados, efecto que opera en forma directa, sin que sea necesario

$\mathrm{N}^{\circ} 3$ inciso final). En concreto, ello permite sostener directamente que dichas limitaciones constituyen una inconstitucionalidad (en este sentido Politoff Lifschitz, Sergio; Matus Acuña; Jean Pierre, "Comentario preliminar al art. 18. Aplicación temporal de la ley penal”. En Politoff y Ortiz (2002) 269 y en Politoff/Matus/Ramírez (2004) 132). Expresamente CurY (2005) 790. Una opinión diversa se puede apreciar en GARRIDo (2007) 378.

40 Politoff/Matus/Ramírez (2004) 570, vinculándolo directamente a razones de paz social basadas en la necesidad de hacer frente a procesos de turbulencia política o social. En un sentido similar, Novoa (2005) 394.

Sobre esta base, Cury (2005) 790, objeta la posición de quienes ven tras la amnistía un instituto equivalente a la derogación. En el mismo sentido, NovoA (2005) 394, no obstante afirmar lo siguiente: "tan completos son los efectos de la amnistía que pudiera equiparársele a una ficción de no haber existido la ley penal que debió ser aplicada a el o los individuos que realizaron, con plena responsabilidad penal, los hechos tipificados legalmente". Directamente en contra: GARRIDO (2007) 378.

42 Cury (2005) 791; Novoa (2005) 393. En contra: Garrido (2007) 378.

43 En el mismo sentido CuRY (como en nota anterior) más allá que haya entendido que una vez cumplida la pena el efecto propio ya no corresponde estrictamente a una extinción de la responsabilidad penal, concepto que el autor identifica con la obligación de cumplir la pena. Asimismo Etcheberry (2004), 248; Una opinión diversa se puede ver en Garrido (2007) 378; Guzmán (2002) 250; Novoa (2005) 394, y Politoff/Matus/Ramírez (2004) 570. Conviene además apuntar que la mayoría de estos autores, Cury (2005) 791; Etcheberry (2004) 250; Guzmán (2002) 250 y Politoff/Matus/Ramírez 570; son partidarios de la idea de que en estos casos se deben restablecer los derechos políticos sin necesidad de que se cumpla el trámite de la rehabilitación, cuando procediere. ETCHEBERRY (2004) 251, aporta como argumento el que la voluntad del Senado (cuando se requiere) ya se ha manifestado al aprobarse la propia ley que concede el amnisticio. 
para ello el cumplimiento de ninguna exigencia adicional, como debiera ser ${ }^{44}$. Ello, pues la amnistía, por el hecho de acordarse, debiera de facto hacer desaparecer todas las consecuencias asociadas a la calificación penal del hecho sobre el que recae, "anulando" directamente todo eventual obstáculo a la procedencia de los sustitutivos (a menos que existan otras condenas) ${ }^{45}$.

Finalmente, también se atribuye este mismo efecto al denominado "indulto general" pues un sector de la doctrina ${ }^{46}$ entiende que se trata de un instituto que detenta un campo más amplio de incidencia respecto al previsto para el indulto particular (que afecta, en exclusiva, al cumplimiento de la pena impuesta ${ }^{47}$ ), considerando especialmente que su acuerdo se encuentra confiado a los cuerpos colegisladores ${ }^{48}$. De acogerse este punto de vista, la dictación del indulto tendría los efectos propios de la extinción de la responsabilidad penal y no limitarse a afectar las condiciones de cumplimiento de la pena impuesta. Debiera por ello contar con un mecanismo automático que permita la total eliminación de los registros y antecedentes penales y, además, impactar en el sentido que nos ocupa en la aplicación de la Ley 18.216. En concreto, la asimilación de efectos llevaría a no exigir plazo alguno a partir de la constatación del "evento" constitutivo del indulto ${ }^{49}$. A este respecto, y si bien no existe un mecanis-

$44 \quad$ Artículo $8^{\circ}$ Decreto Supremo Nº 64 de 1960: “Se eliminará una anotación prontuarial: (...) d) Cuando el prontuariado haya sido favorecido con una ley de amnistía respecto del delito a que se refiere la anotación".

45 De no existir condenas adicionales dicha supresión acarreará igualmente la eliminación completa del prontuario, conforme lo dispone el art. 9 letra a) del Decreto Supremo No 64 de 1960. "Artículo 9 ${ }^{\circ}$. El prontuario penal solo se eliminará: a) Cuando todas las anotaciones registradas en él se hallen en algunas de las condiciones indicadas en el artículo precedente". Por lo dicho anteriormente, resulta objetable que no se disponga de un mecanismo similar para los casos asociados a una derogación formal, en tanto se trata de situaciones que comparten íntegramente sus fundamentos y debieran por ello acarrear el mismo efecto.

46 Lo constata Garrido (2007) 380; Adhiere a ello: Etcheberry (2004) 252. Hay que tener en cuenta que la discusión se plantea a propósito de lo que se denomina es la potencial aplicación del indulto general con efectos retroactivos, más allá que, en el fondo, el centro de la discusión radica en la posibilidad de extensión de los efectos que puede llegar a tener el indulto general.

47 Así lo ratifica el art. $93 \mathrm{~N}^{\circ} 4$ del Código Penal en términos expresos al indicar que " $\mathrm{La}$ gracia del indulto solo permite o conmuta la pena; pero no quita al favorecido el carácter de condenado para los efectos de la reincidencia o nuevo delinquimiento y demás que determinan las leyes".

48 La lógica de sustento se basa en recordar que se trata de un órgano competente incluso para dictar una amnistía, de lo cual se colige que puede asignar a sus decisiones un campo intermedio de efectos. De hecho, mayoritariamente se entiende que en dicho caso (indulto general) se puede llegar incluso a dejar sin efecto a las inhabilitaciones de derechos políticos que requieren acuerdo del Senado, en tanto dicho órgano habrá participado y aprobado la propia Ley de indulto general. Ver en: CuRY (2005) 794.

49 Por el contrario, quienes entienden que conserva su naturaleza en cuanto "indulto" (aplicable por ello solo a los efectos del cumplimiento de las condenas) debería concluir que resulta necesario contar los plazos correspondientes a partir de la fecha en que se dicta. 
mo que haga operativa dicha asimilación (equiparando sus efectos a los de la amnistía respecto de la supresión de los antecedentes prontuariales), nada parece impedir que se reclamen dichas consecuencias por efecto (expreso o tácito) de la propia ley de indulto general ${ }^{50}$.

\section{4) CASOS ESPECIALES}

Antes de concluir parece indispensable que nos refiramos al tratamiento de los efectos que pudiere generar la aplicación del procedimiento previsto en el Decreto Ley $N^{\circ} 409$ de 1932 para la eliminación de los antecedentes que constan en el prontuario penal, en tanto se trata de un régimen que pueden incidir, indirectamente, en la valoración de los "antecedentes previos" de quien es condenado. Otro tanto cabe decir de la presencia de condenas fundadas en el régimen previsto en la Ley 20.084 que regula un sistema especial de responsabilidad para adolescentes que infringen la Ley penal, en atención a lo problemático que resulta el que dicho régimen produzca efectos en la vida adulta de dichos infractores (y con ello, en una eventual responsabilidad penal).

\section{1.) ELIMINACIÓN DE ANTECEDENTES PRONTUARIALES}

Conforme dispone el artículo $1^{\circ}$ del Decreto Ley 409 de 1932, que regula el procedimiento general de eliminación de antecedentes prontuariales, "Toda persona que haya sufrido cualquier clase de condena y reúna las condiciones que señala esta ley, tendrá derecho después de dos años de haber cumplido su pena, si es primera condena, y de cinco años, si ha sido condenado dos o más veces, a que por Decreto Supremo, de carácter confidencial, se le considere como si nunca hubiere delinquido para todos los efectos legales y administrativos, y se le indulten todas las penas accesorias a que estuviere condenado". De esta forma, quien ha cumplido la pena (o la condena) podría hipotéticamente acceder a la supresión de los antecedentes de su prontuario una vez transcurridos dos o cinco años desde dicha fecha, afectando por ello a la posibilidad de acreditar la existencia de una condena previa antes de que se hayan cumplido los plazos de 5 o 10 ańos que respecti-

Sobre las razones para rechazar dicha postura CURY (2005) 794, quien entiende que la caracterización del indulto particular es más bien la caracterización de cualquier tipo de indulto, a riesgo de desnaturalizarlo y mutar en algo diverso. Para dicho autor se trata de una cuestión propia de "la naturaleza de las cosas". También: Garrido (2007) 382.

El único límite posible de imaginar provendría de aquellos condenados que registraren antecedentes en virtud de hechos que no quedaren comprendidos en el indulto general, caso en el cual este efecto concreto se limitaría a la omisión (total y absoluta) del antecedente que corresponda, pero no del prontuario, debiendo someterse el eventual acceso a los sustitutivos conforme corresponda a dichas condenas. 
vamente son exigidos para anular el efecto restrictivo previsto en la Ley $18.216^{51}$. Con ello, se debiera concluir que en dichos casos se encontraría habilitado el acceso a dicho régimen de sustitutivos desde el momento en que se suprimen los antecedentes correspondientes, a pesar de que, en los hechos, no se habrá dado cumplimiento al tiempo exigido en la Ley $18.216^{52}$.

La otra opción consiste en entender que dicha supresión en modo alguno afecta a nivel material a la exigencia prevista en la Ley 18.216, toda vez que su efecto se debiera encontrar acotado a los estigmas generales que ofrece la condena, sin alterar en modo alguno los efectos asociados al régimen o estatuto que rige a la regulación penal. A dichos efectos, siempre existiría la posibilidad de que los órganos encargados de la persecución penal pudiesen recurrir a antecedentes documentales diversos del prontuario penal para acreditar la data de la condena o los términos de su cumplimiento, procedimiento que la jurisprudencia reconoce a veces como válido para la acreditación de la agravante de reincidencia. Sobre dicha base podría mantener plena vigencia la restricción impuesta para acceder a las penas sustitutivas conforme al régimen previsto en general en el art. $1^{\circ}$ de la Ley 18.216 , mientras no se dé estricto cumplimiento a los plazos previstos.

Para resolver esta cuestión se debe tener presente que para la regulación de este mecanismo el legislador tiene en cuenta que "aquellos ex-penados que han demostrado fehacientemente estar regenerados y readaptados a la vida colectiva" deben contar con la posibilidad de que "una vez cumplida su condena y después de haber llenado ciertos requisitos, pasará a formar parte de la sociedad en las mismas condiciones que los demás miembros de ella" 53 , siendo evidente el que se pretende que los efectos asociados al prontuario o registro no lo acompañen en el resto de su vida futura

51 El transcurso de dos años aplica a los casos en que el condenado solo detenta una única infracción, de forma tal que el cumplimiento de dicho plazo habilitaría a la supresión total del prontuario mismo, lo que equivale a equiparar su condición a la de un "primerizo". Tras el lapso de cinco años se obtiene en definitiva el mismo efecto, a pesar de referirse a casos en que se registra más de una condena. Conviene asimismo destacar que, en la medida en que se requiere en ambos regímenes de la satisfacción de la condena (o de la pena), el aspecto problemático se limita a la extensión que debe caracterizar al plazo. Finalmente, se debe tener en cuenta a este respecto que la eliminación de una anotación prontuarial derivada de alguna causa diversa (amnistía, modificación legal que despenalice el hecho, etc.) podría también llegar a influir en la extensión del plazo en el que será posible alcanzar el acceso al régimen de sustitutivos, en aquellos casos en que el condenado registrare alguna condena además de la que resulta "anulada", toda vez que este pasaría de 5 a dos años, a partir de ese momento (y sin perjuicio del cómputo del periodo ya satisfecho).

52 El único caso en que ello sucedería lo constituiría aquel en que se eliminare más de una anotación prontuarial en un lapso de cinco años, cuando estas correspondan a la comisión de simples delitos, pues el tiempo exigido para la supresión del prontuario y el previsto para acceder a los sustitutivos es el mismo.

53 Considerandos, Decreto Ley 409 de 1932. 
si concurren condiciones que permiten afirmar un pronóstico favorable (asociado a una baja probabilidad de recaída en el delito).

De ahí que para que se proceda a la eliminación de los antecedentes prontuariales se haya previsto la sujeción del condenado que ha satisfecho las obligaciones impuestas en su condena ${ }^{54}$ al cumplimiento de un periodo de prueba (o "de seguridad") cuya extensión puede abarcar los ya mentados 2 o $5 \operatorname{años}^{55}$. Dichos objetivos y la exigencia antedicha permiten suponer la aplicación de un régimen más estricto que el ofrecido por el mero transcurso del tiempo, de cara a ofrecer un supuesto que permita revalorizar el pronóstico negativo que impone la condena. Con ello, parece razonable suponer que si la estimación de dicho periodo más intenso de control ha sido considerado suficiente para "rehabilitar" en su condición ciudadana a quien había sido condenado, retirándolo del estatuto de efectos previstos para los condenados o "reiterantes", dicho efecto necesaria-

54 Cabe destacar que todo lo dicho respecto de la exigencia de cumplimiento de la condena resulta plenamente replicable respecto de este requisito previsto para la eliminación de los antecedentes prontuariales. Así, y a pesar de que el contenido literal en este caso también pareciera orientarse a favor de una lectura restrictiva de la exigencia de cumplimiento de la condena (toda vez que establece, en lo pertinente, que "toda persona que haya sufrido cualquier clase de condena (...) tendrá derecho después de dos años de haber cumplido su pena (...)", y el que se exija adicionalmente en el Art. 2 a) del Decreto Ley 409 de 1932, que el condenado haya "observado muy buena conducta en la prisión o en el lugar en que cumplió su condena, cuando se trate de pena de prisión, presidio, reclusión o relegación”, lo que supone el cumplimiento efectivo concurren razones del todo equivalentes a las antes citadas para sostener que la exigencia debe entenderse referida a la satisfacción de la condena, por cualquiera de los mecanismos que produce dicho efecto. A ello se agrega el que la única referencia expresa al cumplimiento de la pena se contiene en el inciso primero del art. $1^{\circ}$ que hemos ya transcrito, refiriéndose todas las demás que contiene el texto al cumplimiento de la condena (arts. 2 letra a), $3^{\circ}$ y $6^{\circ}$ ). Y tampoco parece plantear un obstáculo el que se exija haber observado buena conducta en prisión o en el lugar de cumplimiento, en tanto se trata de una exigencia que, conforme a su propio texto, solo aplica al caso en que se haya debido efectivamente cumplir una pena de encierro o la relegación (respectivamente). Finalmente, entendemos que estas mismas razones avalan el que esta interpretación se haga extensiva a los casos de eliminación de antecedentes penales (y del prontuario) previstos en el Decreto Supremo $N^{\circ} 64$ de 1960, toda vez que en ellos también se opera en base al mismo presupuesto (el cumplimiento de la condena) se recurre a una nomenclatura idéntica y se refieren a la misma materia. Lo dicho se respalda por el Oficio Ord. N ${ }^{\circ} 9020$ de 24 de Diciembre del año 2007, remitido por la entonces Subsecretaria de Justicia, doña Verónica Barahona, a los Secretarios Regionales Ministeriales de Justicia, fecha a partir de la cual el asunto dejó de ser controvertido en las instancias administrativas correspondientes.

55 En la actualidad este opera (si bien en condiciones muy restringidas) como una instancia destinada a favorecer espacios de inserción social, tendiente a neutralizar los factores de riesgo de recaída presentes en el condenado a partir de sus experiencias vitales (incluyendo el delito, la condena y la ejecución de la pena). Al respecto: Espinoza Mavilla, Olga; Martínez Mercado, Fernando (2007) "Políticas de reinserción postpenitenciaria. Eliminación de antecedentes penales en Chile". Revista de Estudios Criminológicos y Penitenciarios, $\mathrm{N}^{\circ} 10$, pp. 458 (con referencias concretas e la operatoria del mecanismo, con datos empíricos, en pp. 461 y ss.). Asimismo: Villagra Pincheira, Carolina (2008) "Hacia una política postpenitenciaria en Chile: desafíos para la reintegración de quienes salen de la cárcel”. Debates Penitenciarios, $\mathrm{N}^{\circ} 7$. 
mente debe alcanzar al régimen de acceso a los sustitutivos penales, permitiendo anticipar las exigencias asociadas a los plazos previstos (en tanto resulta posible estimar satisfechos sus fundamentos). Lo dicho se ratifica si tenemos en cuenta que el efecto previsto a partir de la satisfacción de estos requisitos (cumplimiento de la condena y transcurso del plazo sujeto a control) se describa como un imperativo, asociado a que "se le considere (al condenado) como si nunca hubiere delinquido para todos los efectos legales y administrativos", afirmación que solo se deja leer como una virtual anulación de todos los efectos (aflictivos o estigmatizantes) asociados a la condena ${ }^{56}$, sin que el carácter absoluto de los términos utilizados permita tolerar excepción alguna 57 .

Conviene además advertir que todo lo dicho también resultaría replicable respecto de quienes registraren una sola condena de carácter no aflictivo y que opten por promover su eliminación a través del mecanismo regulado en el art. 8 letras g) y h) del Decreto Supremo 64 de 1960 (alternativa que también alcanza a los menores de 18 años que debieren satisfacer una condena). En dichos casos la diferencia con el Decreto Ley 409 de 1932 se marca en el hecho de que el periodo de observación al que debe someterse el condenado supone, como condición, el solo hecho de carecer de nuevos antecedentes (no conlleva acreditación en ámbitos como la educación o el trabajo) y se extiende a $3^{58}, 5^{59}$ o $10^{60}$ años (en lugar de los 2 años que para estos casos prevé el Decreto Ley 409) ${ }^{61}$. Además, quienes por esta vía eliminaren su única anotación podrán solicitar

56 El estigma asociado a la presencia de una condena penal en el historial de vida del condenado produce restricciones materiales y de acceso en la vida civil (especialmente laboral) que se detonan a partir de cualquier condena. Con detalle y datos empíricos referidos a los sesgos que produce la presencia de antecedentes penales en el acceso al mercado laboral: LARRAURI, Elena; Jacobs, James (2011) "Reinserción laboral y antecedentes penales". Revista electrónica de Ciencia Penal y Criminología, N¹3-09, disponible en: http://criminet.ugr.es/ recpc/13/recpc13-09.pdf [fecha de visita 23 de septiembre de 2014]. Con respecto a la realidad espańola se incluye una cita de referencia a estudios empíricos concretos en p. 4.

57 Lo confirma también la supresión (o "indulto") de los efectos accesorios que opera, conforme a los términos de la ley, a consecuencia del hecho de que se le considere como si nunca hubiere delinquido, en cuanto se trata precisamente de efectos y consecuencias asociadas estrictamente a la condición de penado. Al respecto Mapelli Caffarena, Borja (2006) "Las penas accesorias o la accesoriedad punitiva". Revista de Estudios Penitenciarios. Número Extraordinario 1, Homenaje al profesor Francisco Bueno Arús, 264, pp., p. 28. Asimismo: Muñoz Conde, Francisco; García Arán, Mercedes (2007) Derecho Penal. Parte General. 7a Edición. Valencia: Editorial Tirant lo Blanch, p. 505. Próximo: Cury (2005) 747.

58 Condenas por faltas y condenas de menores de edad con pena aflictiva ( art. 8 letras f) y h), Decreto Supremo No 64 de 1960).

59 Condenas por simples delitos (art. 8 letra g), Decreto Supremo Nº 64 de 1960).

60 Condenas por crímenes (art. 8 letra g), Decreto Supremo Nº 64 de 1960).

61 Los menores de edad condenados a penas no aflictivas tiene derecho a solicitar este efecto una vez cumplida la pena, sin exigencia de plazo alguno de control. (art. 8 letra h), Decreto Supremo $N^{\circ} 64$ de 1960). 
por ese solo hecho la eliminación del propio prontuario ${ }^{62}$. Se excluyen entonces de este mecanismo los casos de condena aflictiva y quienes registran más de una condena (cualquiera fuere la extensión de ellas), condenados que solo pueden optar a la omisión de determinados antecedentes del prontuario ${ }^{63}$.

\section{2.) RÉGimen APLICABLE A LAS CONDENAS IMPUESTAS POR APLICACIÓN DE LA LEY 20.084}

El problema que propone la presencia de condenas fundadas en la responsabilidad penal que se origina en la comisión de ilícitos penales durante la adolescencia, regulados conforme al sistema especial previsto en la Ley 20.084, consiste en determinar si su concurrencia produce el efecto de anular la procedencia de los mentados sustitutivos, tomando como base el que la exigencia prevista en la Ley 18.216 no pareciera plantear distinciones.

Contribuye a dicha afirmación el que las condenas impuestas por aplicación de la Ley 20.084 (condenas de adolescentes) se encuentran sin lugar a dudas sometidas a registro, debiendo incluirse específicamente en el Registro General de Condenas conforme dispone el inciso final del art. 2 del Decreto Ley 645 de 1925. Concretamente, dispone la comunicación de dichos antecedentes a los actores procesales correspondientes para los efectos de "comprobar la reincidencia de los imputados", quedando por ello limitado su uso a las consecuencias de la responsabilidad penal que fueren procedentes sin que se puedan consignar dichas anotaciones en las certificaciones pertinentes relativas a otros fines ${ }^{64}$.

No obstante, de ello no se desprende que los efectos en materia de reincidencia sean aplicables en casos de juzgamiento de nuevos delitos en la forma prevista en el régimen penal general. Y no solo por el hecho de que en este caso en particular no se trate de la valoración precisa de "la reincidencia", concepto que pudiere ser interpretado en un sentido técnico o literal ${ }^{65}$, sino mas bien por el hecho de que se trata de un contenido propio del un régimen especial de responsabilidad penal cuyas particularidades precisamente se oponen a la generación de efectos posteriores en la vida adulta del condenado. En este sentido se ha sostenido que la con-

\footnotetext{
62 Art. 9 letra a) del Decreto Supremo Nº 64 de 1960.

63 Art. 13 del Decreto Supremo Nº 64 de 1960.

64 Se deben excluir entonces de los certificados para manejar vehículos motorizados, para fines particulares y para fines especiales, que no vayan dirigidos a las autoridades mencionadas a los efectos señalados. Al respecto véase el art. 12 del Decreto Supremo Nº 64 de 1960.

65 Sobre este punto y, en general, sobre el régimen aplicable a la reincidencia en la aplicación de la Ley 20.084: Maldonado Fuentes, Francisco (2013) "Reincidencia y responsabilidad penal de adolescentes". Estudios de Derecho Penal Juvenil IV. Informes en Derecho. Centro de Documentación de la Defensoría Penal Pública, pp. 169 a 212.
} 
sideración de efectos penales en el régimen de adultos a partir de los antecedentes propios del régimen de adolescentes vulneraría las Reglas de Beijing $(21.2)$ cuya aplicabilidad se favorece por el texto del art. $2^{\circ}$ de la Ley 20.084; que ello resultaría igualmente incompatible con la orientación de dicho régimen hacia la reinserción, base que lleva a fundar la prohibición de utilizar sus consecuencias en la vida adulta del condenado; y, finalmente, que constituyen sistemas penales completamente independientes (conforme dispone el artículo $10 \mathrm{~N}^{\circ} 2$ del propio Código Penal, en cuanto excluye a los menores de 18 ańos de su aplicación).

A este respecto la jurisprudencia ha sido vacilante hasta la fecha. No obstante recientemente la Corte Suprema se ha inclinado por favorecer esta misma conclusión. En concreto, por sentencia de 17 de septiembre de 2013 recaída en causa Rol n ${ }^{\circ} 4419-13$, la $2^{\circ}$ Sala afirma que el uso de condenas propias del régimen de adolescentes en el sistema de adultos sería una forma de "utilizar esa sanción no ya para hacer efectiva la responsabilidad penal del menor, sino para agravar la responsabilidad por los ilícitos cometidos siendo adulto", advirtiendo además un problema "material, pues esa pena adjudicada siendo adolescente, nuevamente por mandato expreso del citado artículo $20-y$ del artículo $40 N^{\circ} 1$ de la Convención sobre los Derechos del Niño, que fue su fuente informadora- debe orientarse a su "plena integración social" y nada más contrario y alejado a dicha directriz que luego valerse de esa sanción precisamente para incrementar las penas privativas de libertad-cuyo efecto desocializador y despersonalizante no requiere pruebaque el sistema penal de adultos prevé para la generalidad de los delitos" 66 (Considerando $\left.\mathrm{n}^{\circ} 11\right)$. Alude, además, expresamente, al argumento referido al contenido del artículo10 $\mathrm{N}^{\circ} 2$ del Código Penal, declarando a partir de su texto dicho Código no se aplica a personas menores de edad, evidenciando el que se trata de dos clases de responsabilidad (penal) diversas.

Este fallo resulta particularmente relevante, pues a pesar de que la mayoría de la sala considera que dicho contenido no influye en lo dispositivo, la propia resolución justifica la necesidad de expresar un completo desarrollo de este punto con el objeto de "hacer menos incierto para todos los ciudadanos la anticipación de las circunstancias modificativas que podrian incidir en la determinación judicial de las sanciones con que se reprimen criminalmente las conductas tipificadas en la ley" (Considerando tercero), en una especie de Obiter Dictum, cuyo único sentido se orienta a la consideración del criterio en las resoluciones futuras ${ }^{67}$.

66 Corte Suprema. 17 de septiembre de 2013. Rol No 4419-2013. "Contra Max Alexander Ońate Salas”. Disponible en: http://suprema.poderjudicial.cl/SITSUPPORWEB/ [fecha de visita 20 de marzo de 2015].

67 El criterio opuesto había sido sostenido previamente en distintos fallos, paradigmático en causa Rol 7364-2012 de 4 de diciembre de 2012. Corte Suprema. 4 de diciembre de 2012. 
Ahora bien, hay que tener en cuenta que en cualquier caso lo habitual será que de forma preferente tenga lugar lo dispuesto en el art. $8^{\circ}$ letra h) del Decreto Supremo N 64 de 1960 que dispone que tratándose de condenas no aflictivas impuestas por delitos cometidos por menores de edad, se deberá proceder a la eliminación de los respectivos antecedentes en base al solo dato que aporta el cumplimiento de la condena o, en caso contrario (condena aflictiva), por el solo hecho de que hayan transcurrido tres años desde dicho cumplimiento (sin sujeción alguna a medidas o periodos de control o supervisión). Con ello, de no acogerse al mecanismo previsto en el DL 409 de 1932 para obtener la eliminación de dichos antecedentes, bastará el transcurso de dicho lapso para que dichos antecedentes "desaparezcan", a menos que se hubieren acumulado varias condenas (de esta misma o diversa naturaleza ${ }^{68}$ ) o que, si algunas de ellas tuvieren carácter aflictivo ${ }^{69}$, se procurare anticipar dicho término sometiéndose al régimen de control por los correspondientes dos años.

\section{5) CONCLUSIONES Y COROLARIO}

Por todo lo dicho entendemos que se satisface plenamente la exigencia de que la pena esté cumplida a los efectos de la anulación del efecto excluyente del régimen sustitutivos penales previsto en la Ley 18.216, en todos los casos en que han transcurridos los plazos previstos respecto de las siguientes condenas:

Rol No 7364-2012. "Contra Ricardo Robinson Soto Cid”. Disponible en: http://suprema. poderjudicial.cl/SITSUPPORWEB/ [fecha de última visita 20 de marzo de 2015]. también al presupuesto que debe ser valorado para determinar el tiempo de observación del que depende la eliminación de antecedentes conforme lo dispone el Decreto Ley 409 de 1932. Si bien no cabe duda que la presencia de varias condenas de adolescentes llevarán a exigir 5 años de observación, dicha conclusión no es tan clara si la duplicidad exigida se basa en una condena perteneciente a cada régimen o sistema de responsabilidad, precisamente en cuanto se prohíbe considerar en el régimen de adultos el registro propio del sistema de adolescentes. El punto es que no resulta sustentable que el registro pertenezca en exclusiva a uno u otro sistema, siendo más bien común a ambos. De esta forma no se trataría de un caso en que se considere dicho registro en un instituto propio del régimen general de adultos. Por ello corresponderá que en estos casos se exija un periodo de 5 años de observación.

69 Hay que destacar que en este último caso, el ex condenado puede optar por someterse a las demás condiciones establecidas en el Decreto Ley 409 de 1932, y obtener de esta forma la eliminación del extracto en dos ańos (de haber iniciado de inmediato el periodo de control) o, asumir una actitud más pasiva, conformándose con la producción de dicho efecto al tercer año. 
i) Cuando ha tenido lugar el cumplimiento efectivo de la(s) penas(s) originalmente impuesta(s), conforme al tenor literal de la reglamentación vigente ${ }^{70}$.

ii) Cuando ha tenido lugar el cumplimiento efectivo de la condena que ha sido modificada por aplicación de causales que alteran el contenido de las obligaciones que emanan de la responsabilidad penal, a saber:
a) Cuando se hubiere producido una modificación legal a la pena prevista para el delito que, en el caso concreto, produzca el efec- to de atenuar el contenido aflictivo de la sanción ${ }^{71}$;
b) Cuando por aplicación de un indulto (general o particular) se ha reducido la extensión de la pena a cumplir (elimina una pena, reduce su extensión o cuantía, etc.) o se ha reemplazado (y cum- plido) la originalmente impuesta (indulto conmutativo);
c) Cuando ha operado la reducción de condenas la observacia de un comportamiento sobresaliente durante su cumplimiento, conforme a lo dispuesto en la Ley 19.856;
d) Cuando se ha cumplido el saldo de pena pendiente en caso que se hubiere revocado alguna de las penas sustitutivas previstas en la Ley 18.216 de conformidad con lo dispuesto en el art. 25 de dicho cuerpo legal ${ }^{72}$;

iii) Cuando se ha dado cumplimiento cabal a cualquiera de las penas sustitutivas previstas en la ley $18.216^{73}$;

iv) Cuando se ha dado cumplimiento a la pena de prestación de servicios en beneficio de la comunidad que hubiere sustituido a una pena de multa conforme a lo dispuesto en el art. 49 bis del Código Penal; y

70 A este respecto se deben tener en cuenta las particularidades que presentan las concretas modalidades de ejecución de la pena de que se trate, con independencia de que planteen fórmulas que se apartan del contenido aflictivo que las caracteriza de manera medular. Así por ejemplo en las penas privativas de libertad se deberá considerar que el periodo en que el condenado accede (de ser el caso) al régimen de libertad condicional e incluso al periodo de cumplimiento que se reduce por aplicación de lo dispuesto en el art. 8 del DL 321 de 1925, pues se trata de modalidades que forman parte del cumplimiento efectivo de dichas penas (Politoff/Matus/ Ramírez (2004) 569). En el fondo, el cumplimiento de la pena debe entenderse como una exigencia de cumplimiento del régimen legal de ejecución de cada sanción.

71 En dichos casos deberá inicialmente confeccionarse una nueva sentencia que fije estas nuevas condiciones de conformidad con lo dispuesto en el inciso tercero del art. 18 del Código Penal, la que servirá de antecedente para ajustar a ella la exigencia de cumplimiento.

72 Con anterioridad a la Ley 20.603, que modificó sustancialmente el contenido de los sustitutivos penales vigentes en Chile, este efecto solo estaba previsto respecto de la "reclusión nocturna". Hoy en día, todos los sustitutivos operan como formas alternativas de cumplimiento (de ahí que se hable de penas sustitutivas) sin que interrumpan la ejecución de la pena originalmente impuesta de forma condicionada, sino sustituyendo su cumplimiento. El efecto preciso se traduce en que su cumplimiento es abonado en caso de quebrantamiento, conforme dispone el art. 26 de dicho cuerpo legal.

73 Lo dicho también se aplica respecto de las medidas alternativas previstas en este mismo cuerpo legal en forma previa a que su contenido fuere modificado por la Ley 20.603. 
v) Cuando se cumple una pena de reclusión en sustitución de una pena de multa, en caso de quebrantamiento de la pena de trabajos en beneficio de la comunidad que, a su vez, hubiere sido impuesta inicialmente como sustitución de dicha multa, conforme dispone el art. 49 sexies del Código Penal; y

vi) Cuando tiene lugar el perdón del ofendido (en los casos en que procede) y se ha dictado la sentencia condenatoria, con independencia de que se haya iniciado o no el cumplimiento efectivo de la sanción; y

vii) Cuando se ha declarado la prescripción de la pena;

Asimismo, podemos también afirmar que no procede cómputo alguno en aquellos casos en que la condena precedente ha visto afectado su "significado" por la concurrencia de alguna causal que diluya la propia responsabilidad penal inicialmente concurrente, como sucede en casos de derogación del respectivo delito, de amnistía o cuando se ha dictado un indulto de carácter general. Lo propio sucede cuando se han cumplido las exigencias para eliminar las respectivas anotaciones prontuariales y cuando se trata de condenas fundadas en el régimen de responsabilidad penal de adolescentes.

Finalmente, y antes de concluir, debemos dejar constancia que también se ha interpretado la exigencia de cumplimiento de condena en un sentido aún más amplio que el propuesto en las líneas precedentes. Existe en efecto cierta jurisprudencia que entiende que los respectivos plazos se deben computar a partir de la fecha de "imposición de la condena", con total prescindencia a la exigencia de "cumplimiento" que contiene el texto $^{74}$, justificado en razones de eminente carácter práctico asociadas estrechamente a la necesidad de viabilizar el uso de la regla acorde a su fundamento. En concreto, se considera que la dilación que supone el tener que esperar al cumplimiento específico de la condena resultaría del todo innecesaria, en cuanto expresiva de un rigor extraordinario que resulta incompatible con los fines pretendidos (asociados a la conveniencia de favorecer la reinserción) ${ }^{75}$. A dichos argumentos se debe agregar que la

74 De hecho, es posible encontrar jurisprudencia reciente que ha resuelto en este sentido. Así, la Corte de Apelaciones de Concepción, con fecha 10 de mayo de 2013, en causa Rol 2302013, a partir de sostener que "el artículo primero de la Ley 20.603 señala que no se considerarán las penas impuestas dentro de los diez o cinco años anteriores, según corresponda, a la comisión del nuevo crimen o simple delito". Corte de Apelaciones de Concepción: 10 de mayo de 2013. Rol No 230-2013. "Contra Juan Antonio Marambio Fierro". Asimismo, en otra sentencia dictada con fecha 12 de abril 2013, en causa Rol 1101-2013 y, de forma explícita, en sentencia de fecha 4 de abril 2014 dictada en causa Rol 189-2014, donde detalla expresamente que "el plazo se debe computar desde que la sentencia de condena esté firme, y no desde el cumplimiento cabal de la condena” (el subrayado es nuestro).

75 En este sentido se pronuncia la Corte de Apelaciones de Concepción en causa Rol 1892014 (de 4 de abril de 2014) en cuanto sostiene que el criterio "se basa en entender que si se verifica el requisito de cumplimiento de la pena, se debe computar el transcurso del plazo desde 
opinión más generalizada entiende que las opciones de recaída durante el cumplimiento de una condena penal suelen ser más bien reducidas, por el efecto de contención material (inocuizador) que produce de facto la ejecución de la pena.

Dicho criterio parece a primera vista plausible, toda vez que se basa en razones perfectamente funcionales a la lógica y fundamento de la institución. Sin embargo no parece compatible con el tenor literal de la disposición, en cuanto en el texto positivo se asocia directamente el cómputo de las fechas al "evento" constitutivo del "cumplimiento" de las sanciones y no al hito que representa su "imposición”. Con ello, forzoso es concluir que el criterio propuesto se mueve en un campo ajeno al de la interpretación, ofreciendo más bien una crítica a la fórmula escogida por el legislador ${ }^{76}$.

En este plano, tampoco creemos que la fecha de "imposición de las condenas" (y no su cumplimiento) ofrezca utilidad para fundar una lectura sobre el comportamiento futuro esperado o esperable del condenado lo que queda en evidencia si se lo compara con el efecto expresivo asociado al "cumplimiento de la condena" o, inclusive, con el hecho que supone la propia fecha de "comisión del delito". Este último, de hecho, pareciera a nuestro juicio constituir el hito más preciso o relevante a dichos efectos, toda vez que expresa el referente exacto que funda la valoración negativa sobre el comportamiento futuro del condenado que lleva a restringir el acceso a los sustitutivos. De ahí que, si lo relevante es apreciar un efecto inverso a partir de la constatación de "un tiempo sin delito", este parezca precisamente como el dato relevante para iniciar su cómputo.

No se opone a ello la idea de que la ejecución de la condena "neutraliza" dicha valoración pues es un hecho que nada impide la comisión de nuevos delitos en dicho periodo, tanto en el medio cerrado como en el medio libre. Lo dicho se confirma en el tratamiento de la llamada prescripción de la reincidencia, institución que, compartiendo el mismo fundamento, propone desarrollar el cómputo a partir la fecha de "comisión del hecho" en forma literal 77 , ofreciendo una base normativa que por ello

la sentencia firme y no desde el cumplimiento pues esta es la forma de hacer realmente viable la aplicación de las penas sustitutivas, y no convertirlas en algo excepcional. La interpretación contraria, haría de los plazos un rigor temporal extraordinario". CA de Concepción Rol No 189-2014, p. 5. Un fundamento similar se aprecia en sentencia de la Corte de Apelaciones de La Serena de 9 de abril de 2013 recaída en causa Rol N 70-2013.

76 Cuestión diversa hubiera sido si el legislador hubiere prescrito que "no se considerarán las condenas por crimen o simple delito [impuestas] [dictadas], respectivamente, cinco o diez años antes de la comisión del nuevo ilícito [que se encuentren cumplidas]" o "no se considerarán las condenas [cumplidas que se hubieren impuesto] por crimen o simple delito, respectivamente, cinco o diez años antes de la comisión del nuevo ilícito".

77 Lo destaca Etcheberry (2004) 35: "Esta prescripción se cuenta desde la comisión del hecho (no desde la condena ni desde el cumplimiento de ésta)") 
podría brindar utilidad para la aplicación analógica (en favor del reo) de dicho criterio.

\section{BIBLIOGRAFÍA}

- Caballero Bellido (2006) Ana Isabel, Defenderse desde la Cárcel, GTZ-Chile.

- Carnevali, Raúl / Maldonado F., Francisco (2013) “El tratamiento penitenciario en Chile”, en Arocena G. (Director), El tratamiento penitenciario. resocialización del delincuente, Buenos Aires, Edit. Hammurabi, pp. 113 a 158.

- Couso Salas, Jaime / Hernandez Basualto, Héctor (directores) (2011) Código Penal Comentado. Parte General. Doctrina y Jurisprudencia, Santiago de Chile, Edit., Abeledo Perrot.

- Cury Urzúa, Enrique (2005) Derecho Penal. Parte General, 7a Edición, Santiago, Ediciones Universidad Católica de Chile.

- De La Fuente Hulaud, Felipe (1990) "Sobre el concepto de responsabilidad criminal en nuestro Código Penal", en Revista de Derecho de la Pontificia Universidad Católica de Valparaiso, Vol. XIII, pp. 113 a 118 .

- Etcheberry O., Alfredo (2004) Derecho Penal. Parte General, 3a Edición, Santiago, Edit. Jurídica de Chile.

- Espinoza, Olga / Martínez, Fernando (2007) "Políticas de reinserción postpenitenciaria. Eliminación de antecedentes penales en Chile", en Revista de Estudios Criminológicos y Penitenciarios $\mathrm{N}^{\circ}$ 10, pp. 454 a 475.

- Fuenzalida, Iván (2009) "Anotaciones Prontuariales de los Adolescente: Un Tema Pendiente.", en Justicia y Derechos del Niño No 11, Santiago, Unicef.

- Garrido Montt, Mario (2007) Derecho Penal. Parte General (T. I y II), $4^{\mathrm{a}}$ ed. Santiago, Edit. Jurídica de Chile.

- Gracia Martin, Luis (2006) Tratado de las consecuencias jurídicas del delito, Valencia, Edit. Tirant lo Blanch.

- Guzmán Dalbora, José Luis (2009) La pena y la extinción de la responsabilidad penal, Montevideo/Buenos Aires, Edit. BdeF.

- Guzmán Dalbora, José Luis (2002) Comentario al título V del Libro I, en Politoff/Ortiz (Dir.), Matus (Coord.), "Texto y Comentarios del Código Penal Chileno”, Tomo I, Libro Primero, Parte General, Santiago, Edit. Jurídica de Chile.

- Hassemer, Winfried (1999) “¿Por qué y con qué fin se aplican las penas? Sentido y fin de la sanción penal”, en, del mismo, Persona, Mundo y responsabilidad, Valencia, Edit. Tirant lo Blanch. 
- Larrauri, Elena, Jacobs, James (2011) "Reinserción laboral y antecedentes penales", en Revista electrónica de Ciencia Penal y Criminologia, $\mathrm{N}^{\circ} 13-09$. Disponible en http://criminet.ugr.es/ recpc/13/recpc13-09.pdf [Consultado por última vez el 22 de Septiembre de 2014]

- Maldonado Fuentes, Francisco (2013) "Reincidencia y responsabilidad penal de adolescentes", en Estudios de Derecho Penal Juvenil IV (Informes en Derecho), Centro de Documentación de la Defensoría Penal Pública, pp. 169 a 212.

- Martínez Mercado, Fernando (2008) Asistencia postpenitenciaria en Chile, Santiago, Ril Editores.

- Mapelli Caffarena, Borja (2006) Las penas accesorias o la accesoriedad punitiva en VVAA, Revista de Estudios Penitenciarios, Volumen Extra en Homenaje al Profesor Francisco Bueno Arús, Madrid, Dirección General de Instituciones Penitenciarias, Ministerio del Interior, pp. 59 a 74.

- Mapelli Caffarena, Borja / Terradillos Basoco, Juan (1990) Las consecuencias jurídicas del delito, Madrid, Edit. Civitas.

- Mapelli Caffarena, Borja (2005) Las consecuencias jurídicas del delito, Madrid, Edit. Civitas.

- Matus Acuña, Jean Pierre (2002) en Politoff/Ortiz (Directores), Matus (Coordinador), Texto y Comentarios del Código Penal Chileno, Tomo I, Libro Primero, Parte General, Santiago, Edit. Jurídica de Chile.

- Mir Puig, Santiago (2007) Derecho Penal. Parte General, 7a ed., Barcelona, Edit. Reppetor.

- Muñoz Conde, Francisco / Garcia Arán, Mercedes (2007) Derecho Penal. Parte General, Valencia, Edit. Tirant lo Blanch.

- Novoa Monreal, Eduardo (2005) Curso de Derecho Penal chileno, $3^{\text {a }}$ Edición, Santiago, Edit. Jurídica de Chile.

- Obreque Vivanco, Luis (2010) Los servicios penitenciarios en Chile, Gendarmería de Chile.

- Ortiz de Filippi, Hugo (1990) De la extinción de la responsabilidad penal, Santiago, Ediar Conosur.

- Ortiz, Luis y Arévalo, Javier (2013) Las Consecuencias jurídicas del delito, Santiago, Editorial Jurídica de Chile.

- Piña Rochefort, Juan Ignacio (2005) Algunas consideraciones acerca de la (auto) legitimación del derecho penal, en Gómez JARA (Editor) "Teoría de sistemas y derecho penal. Fundamentos y posibilidades de aplicación", Granada, Edit. Comares.

- Politoff, Sergio; Matus A., Jean Pierre; Ramírez, María Cecilia (2004) Lecciones de Derecho Penal Chileno, Parte General y Parte especial. 2a Edición, T.I., Santiago, Ed. Jurídica de Chile. 
- Ríos López, Cristián (2004) Omisión y eliminación de antecedentes penales, Santiago, Editorial Jurídica Congreso.

- Rodríguez Collao, Luis (2011) "Naturaleza y fundamento de las circunstancias modificatorias de la responsabilidad criminal", en Revista de Derecho de la Pontificia Universidad Católica de Valparaiso, Vol. XXXVI, 1 semestre, pp. 397 a 428.

- Soto, Rosa / Echeverría, Germán: "Eliminación de antecedentes penales", en "La reinserción en el sistema penitenciario chileno. Ejecución de Penas y reinserción social", en Boletín jurídico del Ministerio de Justicia No 4-5, pp. 152 a 155.

- Vargas Vivanco, Juan Enrique (1994) La extinción de la responsabilidad penal, Santiago, ed. ConoSur.

- Villagra Pincheira, Carolina (2008) Hacia una politica postpenitenciaria en Chile, Ril Editores.

- - "Hacia una política postpenitenciaria en Chile: desafíos para la reintegración de quienes salen de la cárcel", en Debates Penitenciarios $\mathrm{N}^{\circ}$ 7, CESC, 2008.

- Zúñiga SAN Martín, Ana María (1991) Legislación sobre omisión y eliminación de antecedentes penales, Santiago, Edit. Jurídica de Chile.

\section{DOCUMENTOS}

- Biblioteca del Congreso Nacional, "Historia de la Ley $N^{\circ}$ 20.603. Modifica la ley 18.216, que establece medidas alternativas a las penas privativas o restrictivas de libertad". Disponible en http:// www.leychile.cl/Navegar/scripts/obtienearchivo?id=recursoslegal es/10221.3/37271/1/HL20603.pdf [fecha de última visita 22 de Septiembre de 2014]

- Centro de Estudios en Seguridad Ciudadana (Cesc), Instituto de Asuntos Públicos, Universidad de Chile, "Estudio modelo y medición de la reincidencia de adolescentes y jóvenes infractores de la ley penal', agosto, 2012. Disponible en http://www.sename.cl/wsename/ otros/uchile/Informe_Final_Reincidencia_medicion_2008.pdf [fecha de última visita 22 de Septiembre de 2014]

\section{JURISPRUdenCia CitAdA}

- Corte de Apelaciones de Concepción: 4 de abril de 2014. Rol No 189-2014. "Contra Vicente Enrique Hermosilla Leiva”.

- Corte de Apelaciones de Concepción: 10 de mayo de 2013. Rol No 230-2013. "Contra Juan Antonio Marambio Fierro".

- Corte de Apelaciones de Concepción: 12 de abril de 2013. Rol No 1101-2013. 
- Corte de Apelaciones de La Serena: 9 de abril de 2013. Rol No 70-2013. "Contra Dyan Gonzalo Díaz Lamas".

- Corte de Apelaciones de Talca: 17 de marzo de 2014. Rol No 912014. "Contra Iván Marcelo Carrasco Morandé".

- Corte de Apelaciones de Temuco: 2 de mayo de 2007. Rol No 486-2007.

- Corte Suprema: 17 de noviembre de 2011. Rol No 9251-2010. "Contra Wilfred Rodrigo Arenas Peñaloza".

- Corte Suprema. 4 de diciembre de 2012. Rol No 7364-2012. "Contra Ricardo Robinson Soto Cid".

- Corte Suprema. 17 de septiembre de 2013. Rol No 4419-2013. "Contra Max Alexander Oñate Salas". 